\title{
Highly Turbocharging a Restricted, Odd Fire, Two Cylinder Small Engine - Design, Lubrication, Tuning and Control
}

\author{
William Attard, Harry C. Watson and Steven Konidaris \\ University of Melbourne
}

Copyright $@ 2006$ SAE International

\begin{abstract}
This paper describes the mechanical component design, lubrication, tuning and control aspects of a restricted, odd fire, highly turbocharged (TC) engine for Formula SAE competition. The engine was specifically designed and configured for the purpose, being a twin cylinder inline arrangement with double overhead camshafts and four valves per cylinder. Most of the engine components were specially cast or machined from billets.
\end{abstract}

A detailed theoretical analysis was completed to determine engine specifications and operating conditions. Results from the analysis indicated a new engine design was necessary to sustain highly TC operation. Dry sump lubrication was implemented after initial oil surge problems were found with the wet sump system during vehicle testing. The design and development of the system is outlined, together with brake performance effects for the varying systems.

Tuning an odd fire engine with an intake restriction and upstream throttle location was explored together with varying injector locations and manifold geometry. To improve engine efficiency, turbocharging and specific engine downsizing were employed in conjunction with a lean burn strategy at low brake mean effective pressure (BMEP). This engine package and tuning strategy resulted in the Melbourne University Formula SAE vehicle being very successful in competition, finishing first in the fuel economy event at the 2004 Australasian competition. Peak BMEP values of 25 bar, believed to be the highest recorded for small engines on pump gasoline were also achieved.

\section{INTRODUCTION AND BACKGROUND}

The design objectives for the engine featured specific downsizing when compared to the typical four cylinder $600 \mathrm{~cm}^{3}$ maximum capacity engines used in the Formula. Downsizing had obvious packaging advantages including large reductions in mass, physical size and centre of gravity (CoG) height, which all contributed to improving the dynamic performance of the Formula vehicle $[1,2,3,4]$. A specifically designed downsized engine also allowed the positioning of many major components, including manifolds and the turbocharger to suit Formula applications. Brake power could also be increased, as the maximum mass flow was limited by the mandatory $20 \mathrm{~mm}$ diameter intake restriction. If the restriction could be choked, delivered power would increase due to the reduction in frictional losses associated with the smaller capacity $[1,2,3,5]$.

To compensate for the reduced capacity, the engine would feature high pressure ratio turbocharging with maximum boost values dictated by turbocharger limits. Turbocharging offered additional benefits, including maintaining maximum mass flow through the restrictor over a wide speed range via boost regulation together with efficiency gains $[3,6,7,8,9]$. This had advantages in reducing fuel consumption and minimising gear shifting for much of the Formula competition $[1,2,3]$.

The engine was installed into successive MUR Motorsport vehicles in 2003 and 2004 and became the first prototype engine to successfully compete in the competition's 25 year history. The final version is displayed in Figure 1.
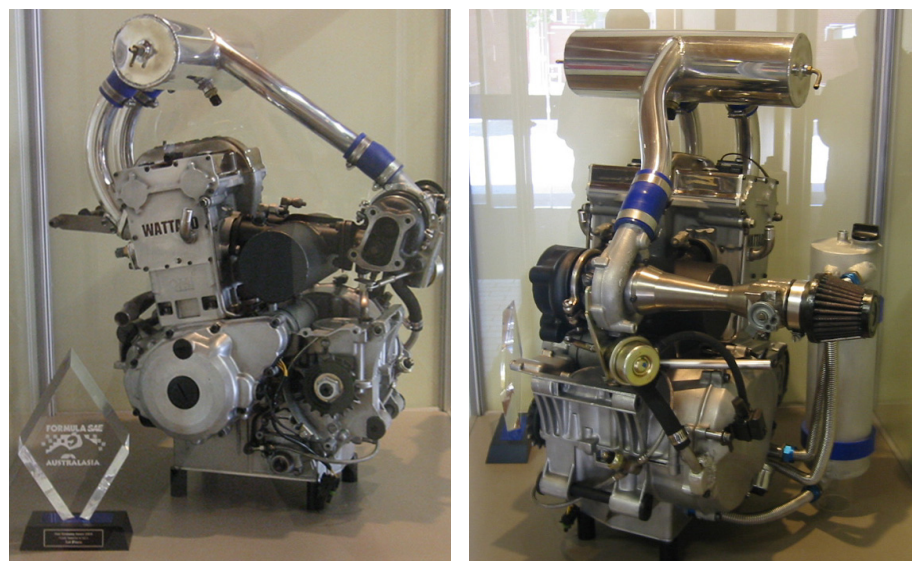

Figure 1: The UniMelb 'WATTARD' engine together with the fuel economy trophy from Formula SAE-Australasia 2004. 


\section{THEORETICAL ANALYSIS}

\section{ENGINE CAPACITY AND CONFIGURATION}

The engine capacity was selected with the aid of Figure 2 , which shows the predicted volumetric efficiency ( $\left.\eta_{\mathrm{VOL}}\right)$ needed to maintain sonic flow in the restrictor for varying engine capacities and operating conditions. A validation point for the model simulation is shown with an experimental result from the team's previous Suzuki GSX-R600 engine. On the basis that a boost pressure ratio of $3.2\left(250 \% \eta_{\mathrm{VOL}}\right.$ assuming losses) is the expected turbocharger limit, an engine size of 400 to $450 \mathrm{~cm}^{3}$ with an operating speed range of $6000-10000$ $\mathrm{rev} / \mathrm{min}$ was selected.

The engine configuration was heavily influenced by the turbocharger. A larger number of cylinders reduced the flow velocity fluctuations experienced by the exhaust turbine but increased frictional losses due to the greater piston rubbing area. The final design featured a two cylinder in-line configuration as a compromise between the competing affects.

\section{$\eta_{\text {VOL }}(\%)$}

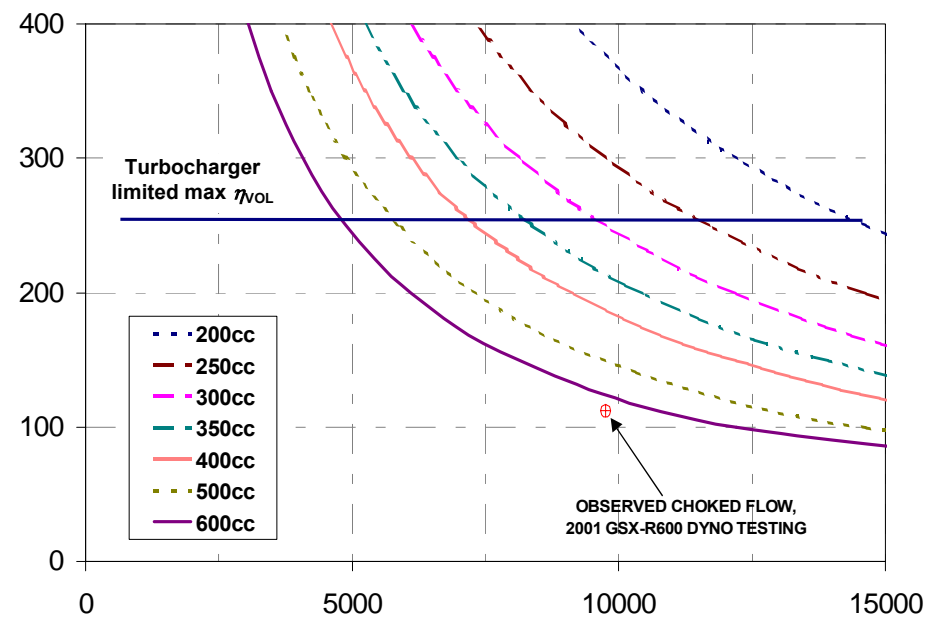

Engine Speed (rev/min)

Figure 2: Predicted $\eta_{\text {VOL }}$ needed to maintain sonic flow in the restrictor for varying engine capacities and operating conditions.

\section{MANIFOLD DESIGNS}

The design and layout of the plenums in between the compressor, engine and turbine were important factors in offsetting the flow pulses, as an uneven firing order was selected for engine balance reasons. Each of the plenums adopted Watson's KEC rolling flow design, where the kinetic energy of the flow is conserved in a vortex about the axis of the plenum [1,2]. The design can be seen pictorially in the CAD image of Figure 3. To determine the size of the plenums, manifold design and valve timing events, an extensive series of simulations were undertaken using Ricardo WAVE ${ }^{\circledR}$. Figure 4 displays the model and predicted results [5].

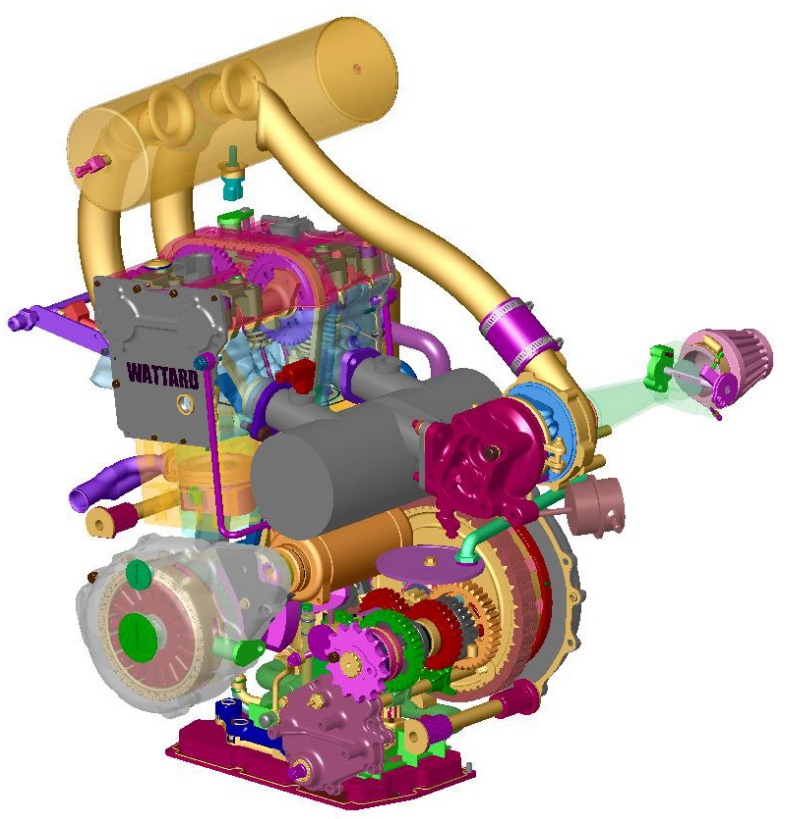

Figure 3: CAD image of the 'WATTARD' TC engine showing the turbocharger location and the manifold and plenum designs.
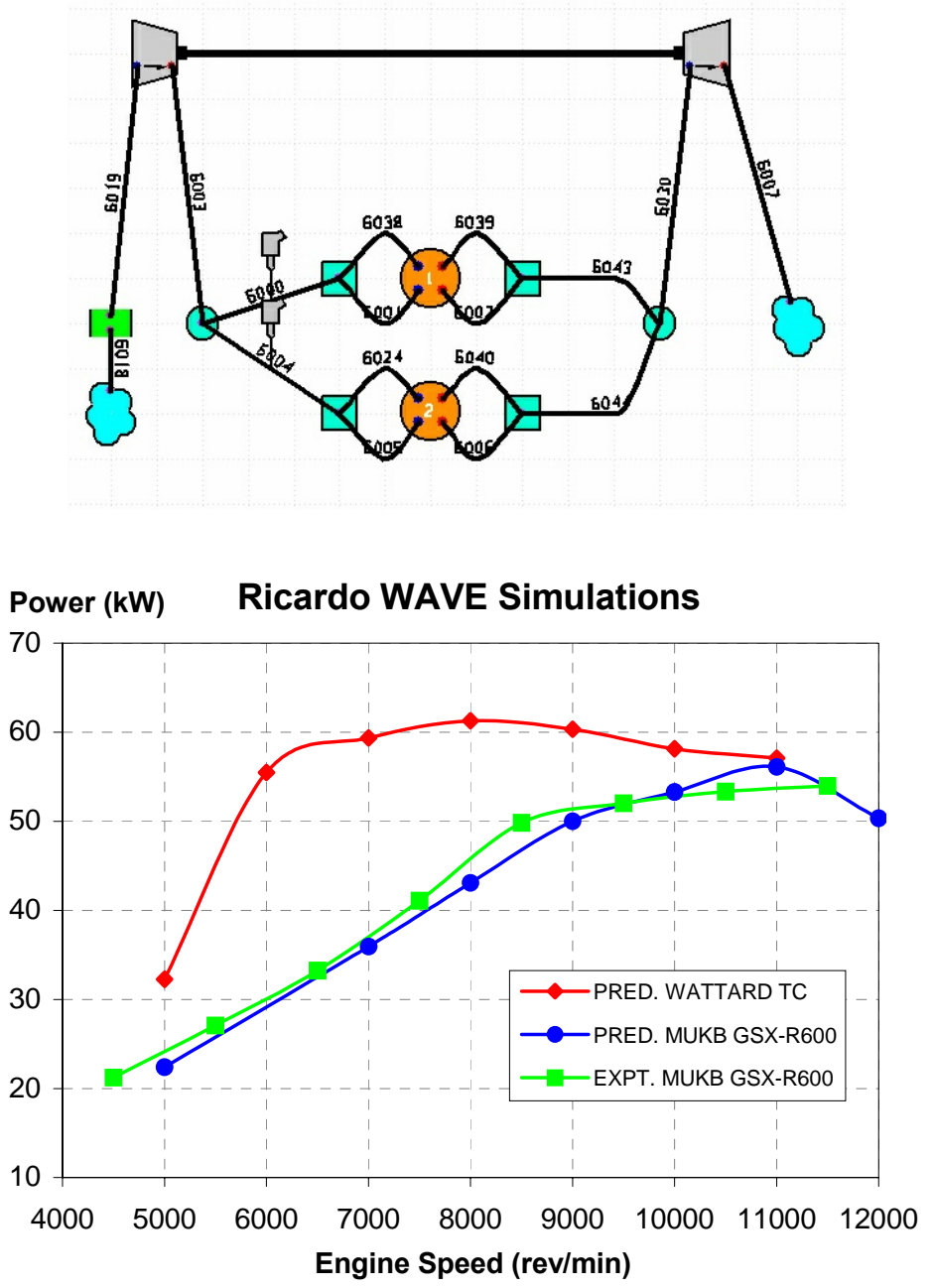

Figure 4: (upper): WAVE $\AA$ model used for TC optimisation. (lower): Simulation results for the TC version and the team's previous Suzuki GSX-R600 engine, with GSX-R600 experimental results used for model validation. 


\section{ENGINE DESIGN AND SPECIFICATION}

Table 1 displays specifications for the final TC version, with a sectional view of the engine design in Figure 5.

Table 1: Specifications for the UniMelb 'WATTARD' engine.

\begin{tabular}{|ll|}
\hline BRAND & UniMelb 'WATTARD' \\
TYPE & Parallel twin, \\
& 4 stroke SI, \\
& Liquid-cooled, \\
& Integral clutch/ transmission \\
CAPACITY & $433.8 \mathrm{~cm}^{3}$ \\
BORE X STROKE & $69 \times 58 \mathrm{~mm}$ \\
FIRING ORDER & Unequal $\left(0^{\circ}, 180^{\circ} \mathrm{CA}\right)$ \\
COMPRESSION RATIO & $10.0: 1$ \\
COMBUSTION CHAMBER & Pent roof, \\
& Central spark plug \\
VALVE ACTUATION & 8 -valve DOHC \\
VALVE TIMING & IVO $24^{\circ}$ BTDC \\
& IVC $72^{\circ}$ ABDC \\
& EVO $57^{\circ}$ BBDC \\
LUBRICATION & EVC $9^{\circ}$ ATDC \\
INTAKE & Dry sump \\
& 20 mm restrictor - Dall venturi \\
& KEC manifold with PFI, \\
EXHAUST & 4.5 L plenum volume, \\
& 350 mm primary intake length, \\
ENGINE MANAGEMENT & KEC manifold \\
TURBOCHARGER & 2.5 L plenum volume \\
CLUTCH & Motec M4 EMS \\
TRANSMISSION & Garrett GT12 (modified) \\
& Multi wet plate \\
& Constant mesh, \\
& 3 forward gears \\
&
\end{tabular}

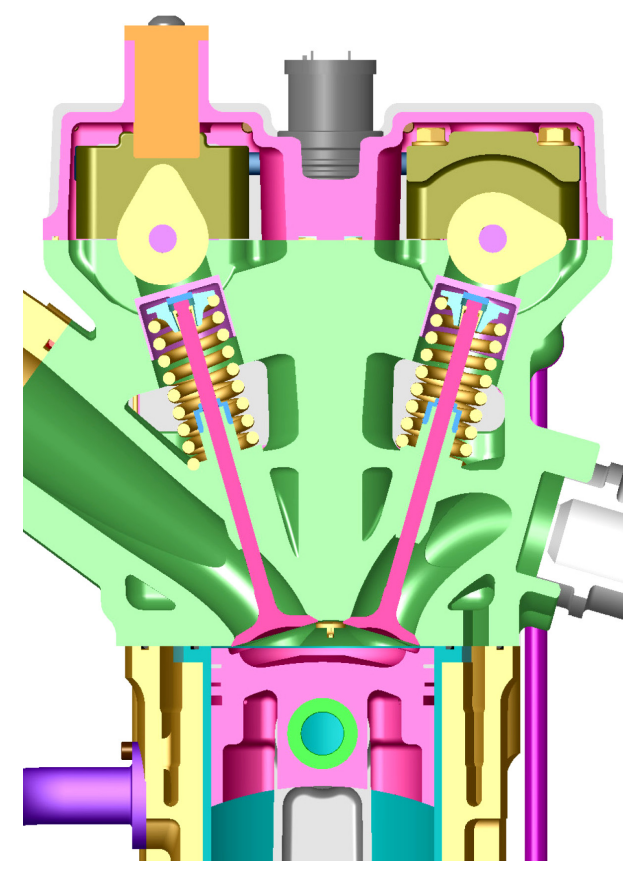

Figure 5: Engine sectional view, highlighting the cylinder head, barrel and reciprocating assembly.
The design drew upon the team's previous experience in producing small TC engines for a larger engine task, $[9,10,11]$. The $434 \mathrm{~cm}^{3}$ twin cylinder in-line arrangement featured double overhead camshafts and four valves per cylinder. The gears and change mechanism in the crankcase were designed to give a wide ratio three speed transmission compatible with the constant power concept of the engine. This had the advantage in reducing the amount of gear shifting required for much of the Formula competition $[1,2]$. The design process involved a number of interesting findings, which led to some new concepts that will be further discussed below.

\section{PISTON AND CYLINDER}

The twin cylinder barrel was machined from billet and featured a novel gasketless interface to couple an aluminum cylinder head to an open deck design cylinder block, as depicted in Figure 6. The design had many advantages for high BMEP applications, including block structural integrity improvements and heat transfer benefits, which reduced knock tendency [12]. The oil jet cooled, custom forged pistons received considerable development. The final design featured a reduced compression ratio of 10:1 and an increase in the number of rings from two to three in order to reduce blow-by and improve heat rejection.

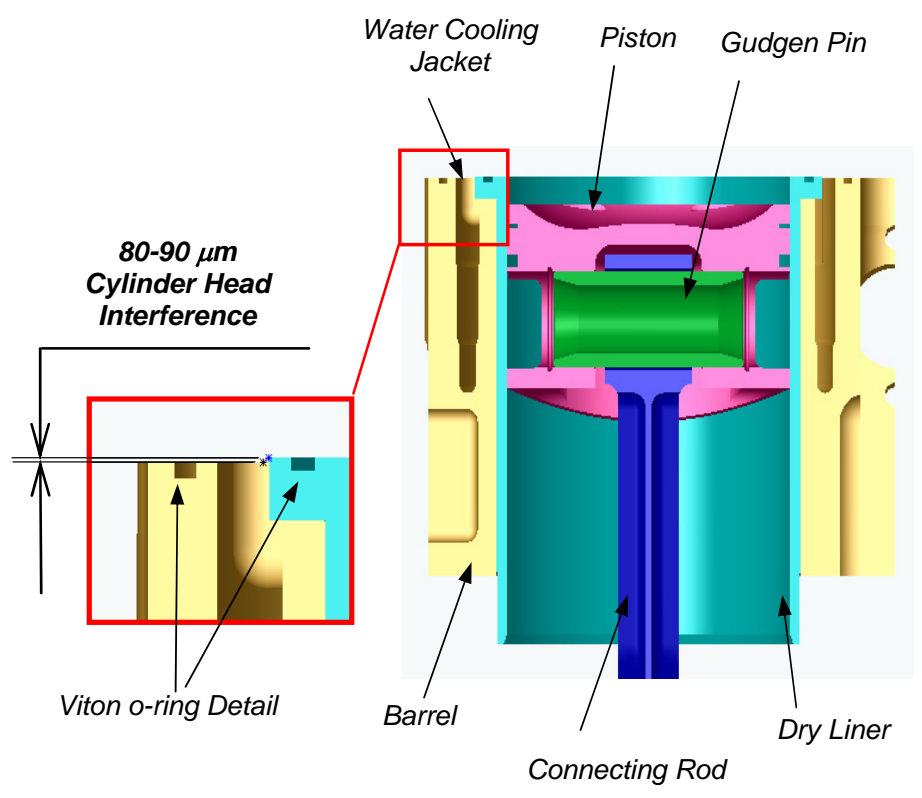

Figure 6: Sectional view highlighting the novel gasketless cylinder head/ block interface, used successfully to couple an aluminum cylinder head to an open deck design cylinder block.

\section{CONNECTING ROD AND CRANKSHAFT}

The specially designed and machined connecting rods are shown in Figure 7 together with the FEM analysis in Figure 8. At the same mass, the I section rod had lower compressive stresses at peak load and thus was adopted. 

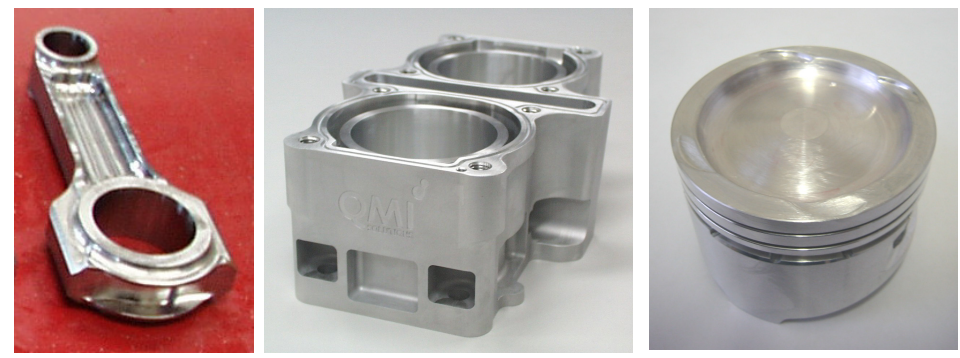

Figure 7: The special requirements and operating conditions of this engine facilitated the design, manufacture and development of many unique components, including the connecting rod, barrel and piston assemblies depicted above.

\section{CONNECTING ROD FEM ANALYSIS}
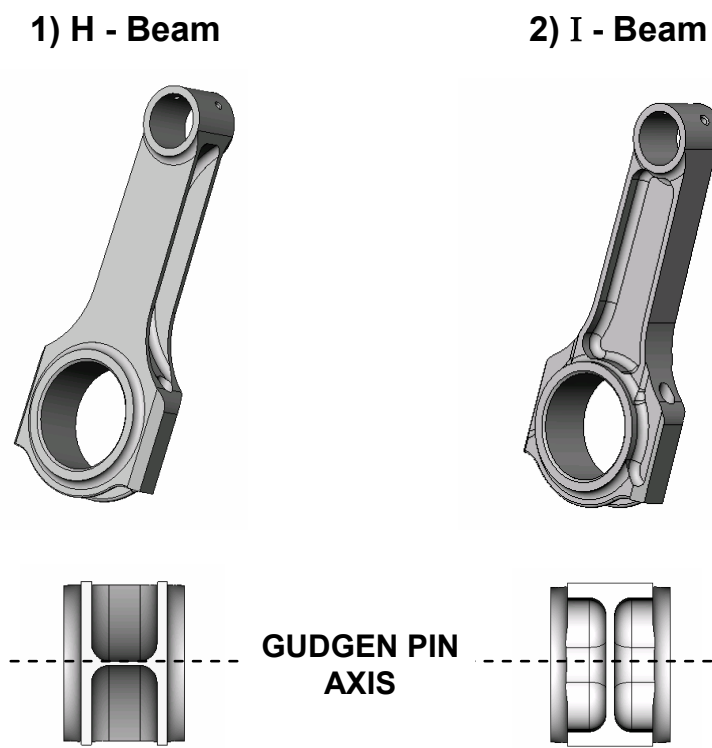

GUDGEN PIN
AXIS
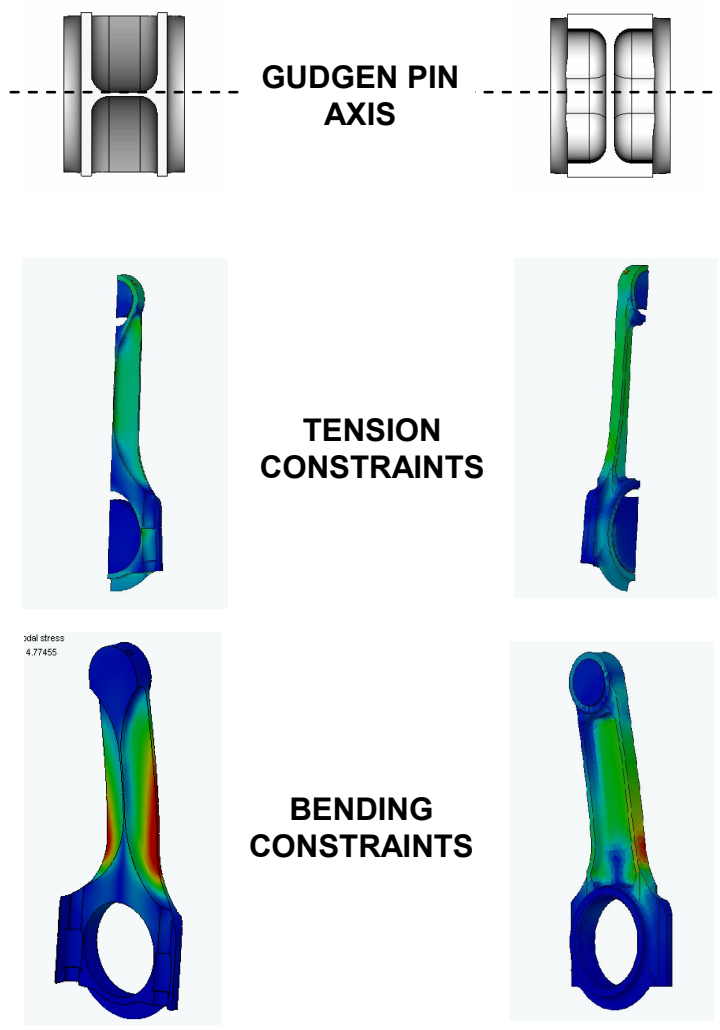

Figure 8: Evaluation of $\mathrm{H}$ and $\mathrm{I}$ beam connecting rods favoring the adopted latter design.
The original crankshaft design featured a $100 \%$ rotating, $0 \%$ reciprocating balance ratio in order to minimise rotational inertia and thus improve engine acceleration. However excessive vertical vibration caused by the induced couple, resulted in a final design which consisted of a $100 \%$ rotating, $50 \%$ reciprocating balance ratio, to minimse the peak vibrational amplitude. Loading for the FEM analysis shown in Figure 9 was determined from a combined combustion and inertia model, developed by the first author. The higher peak stresses in cylinder two's crankpin are a result of the transmission drive path.

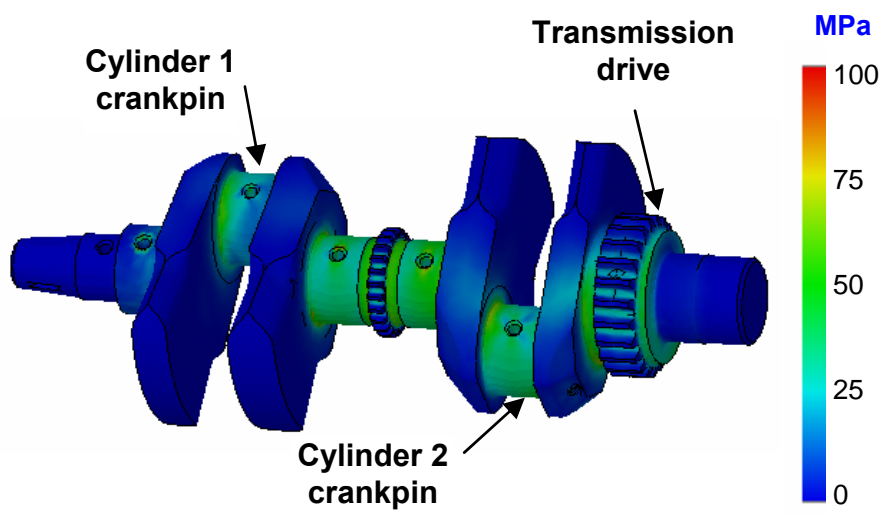

Figure 9: Crankshaft evaluation with FEM and dynamic analysis. Note the higher stresses in cylinder two's crankpin due to the transmission drive path.

\section{TUNING STRATEGY}

The ignition tuning strategy involved finding the minimum spark advance for maximum brake torque (MBT-ST) or in the case when ignition timing was knock limited, the knock limited spark timing (KL-ST). The first stage of knock control would rely on traditional methods involving varying degrees of spark retard and/or fuel enrichment [3], albeit with the penalty of increased fuel consumption.

The lambda tuning strategy varied depending on the load condition, with lean and stoichiometric mixtures targeted at light and medium loads to improve efficiency and reduce fuel consumption. Richer mixtures were used at heavier load conditions associated with brake performance. This improved brake output and provided component protection due to the reduced combustion temperatures, which further enhanced engine reliability.

Fuel injection timing was varied to achieve maximum brake torque (MBT - injection timing), using hydrocarbon $(\mathrm{HC})$ emissions as an indicator of mixing. For assessing air fuel ratio (AFR) and exhaust emissions, the exhaust gas composition was measured in each cylinder's header, using two non dispersive infra red (NDIR) five-gas exhaust analysers.

The employed tuning strategy had significant relevance to Formula SAE applications, as one of the five dynamic 
events featured fuel economy performance. This allowed the engine to conserve fuel when the driver required little power, with significant power increases upon driver demand. Further details of the tuning strategy are given in Table 2 with corresponding BMEP values. Please note that all brake data presented in this paper corresponds to the performance at the gearbox output shaft and not at the crankshaft. This is due to the engine design featuring an integral clutch and constant mesh gearbox within the crankcase. Performance at the crankshaft is expected to be marginally higher, due to the reduction in parasitic losses associated with driving the transmission components. A detailed description of the experimental setup has previously been documented [3].

Table 2: Tuning strategy employed over the varying load conditions.

\begin{tabular}{|c|c|c|c|}
\cline { 2 - 4 } \multicolumn{1}{c|}{} & \multicolumn{3}{c|}{ LOAD CONDITION } \\
\cline { 2 - 4 } \multicolumn{1}{c|}{} & Light & Medium & Heavy \\
\hline $\begin{array}{c}\text { Corresponding } \\
\text { BMEP (kPa) }\end{array}$ & $<300$ & $300-600$ & $>600$ \\
\hline $\begin{array}{c}\text { Corresponding } \\
\text { MAP estimate (kPa) }\end{array}$ & $<60$ & $70-80$ & $>80$ \\
\hline Targeted $\lambda$ & $1.1-1.2$ & 1 & 0.9 \\
\hline Spark Timing & MBT & MBT & MBT or KL \\
\hline $\begin{array}{c}\text { PFI Injection } \\
\text { Timing }\end{array}$ & MBT & MBT & MBT \\
\hline
\end{tabular}

\section{DEVELOPMENT METHODOLOGY}

Testing commenced in a variety of normally aspirated (NA) configurations running to maximum speed before initiating boosted development. This had major advantages in developing the prototype engine under reduced combustion loading, thus ensuring engine reliability. Lighter loading also allowed a base calibration to be set, with high safety margins, as the authors tried to find the limits of operation. Performance was also gauged and compared to previous OEM motorcycle engines used in Formula competition $[1,2,3]$.

Carburetion was chosen for initial engine commissioning as it significantly reduced the complexity during the initial calibration phase. Ignition timing was set through the engine management system (EMS) with the carbureted mass flow device self controlling fuel mixtures after initial jetting. This was extremely helpful in troubleshooting other areas as the system was independent of all electronics and sensors and thus focus could be placed on developing the internals of the custom engine. Once engine reliability was ensured, the sequential port fuel injection (PFI) system was fitted, followed by boosted running. It was expected that the CR would need to be reduced for boosted operation and provisions were made in the piston design to facilitate this requirement.

Boosted operation initially commenced with an externally driven positive displacement Rootes type supercharger. Coupling of this system to the engine was achieved by installing a flexible duct from the outlet of the externally driven supercharger to the intake assembly. Manifold absolute pressure (MAP) was controlled by varying the throttle position since the throttle body/restrictor system was located between the supercharger and the intake manifold. Supercharging was used to establish parametric constraints in order to find the engine's limitations under mild boost with no exhaust influence. A maximum MAP of $150 \mathrm{kPa}$ was desired to evaluate knock severity at low engine speeds and to ensure engine reliability at high compression ratio (CR). The supercharged (SC) data provided valuable insight into the engine modifications needed to sustain high pressure ratio turbocharging [3].

Maximum pressure ratios in the TC mode at wide open throttle (WOT) were dictated by intake restrictor choking limits and corresponding engine speeds. The objective was to maintain a choked restricted inlet at the lowest possible engine speed to broaden and increase the delivered power $[1,2,3,4]$. Thus, maximum levels were dictated by turbocharger limitations and were expected to be greater than $250 \mathrm{kPa}$ MAP, which was needed to produce sonic flow through the intake restrictor at mid range speeds. Boost regulation was required to maintain sonic conditions and avoid excessive turbocharger losses $[13,14]$. This was achieved using the turbocharger internal wastegate, which bypassed exhaust flow past the turbine. A diaphragm operated actuator with reference to MAP controlled wastegate movement, with the reference signal manipulated via a bleed valve controlled through the EMS. This allowed boost pressure to be electronically controlled at user defined functions of engine speed and throttle position (TP).

Engine calibration was performed in accordance with the tuning strategy, defined in Table 2 . If knock control could not be achieved through the EMS using tuning strategies, the CR would be decreased in accordance with the knock severity and testing would be continued to find the limits of operation. The knock (KL) and damage limit (DL), previously published by Rothe [15], were used to determine if $\mathrm{CR}$ reductions were needed to ensure engine reliability. The knock amplitude (KA) required to find these limits is defined as the zero to peak pressure of the high pass filtered cylinder pressure.

$$
\begin{aligned}
& >\mathrm{KL} \quad 1 \% \text { cycles with } \mathrm{KA}>4 \text { bar } \\
& >\mathrm{DL} \quad 1 \% \text { cycles with } \mathrm{KA}>20 \text { bar }
\end{aligned}
$$

\section{TESTING AND DEVELOPMENT}

A two year duration engine development program commenced after initial engine commissioning. This involved fixed speed dynamometer testing coupled with transient testing as shown in Figure 10, with the installation of the engine into two successive Formula SAE vehicles to evaluate performance and reliability. This paper will focus on the issues faced with the lubrication, tuning and control aspects associated with development. 


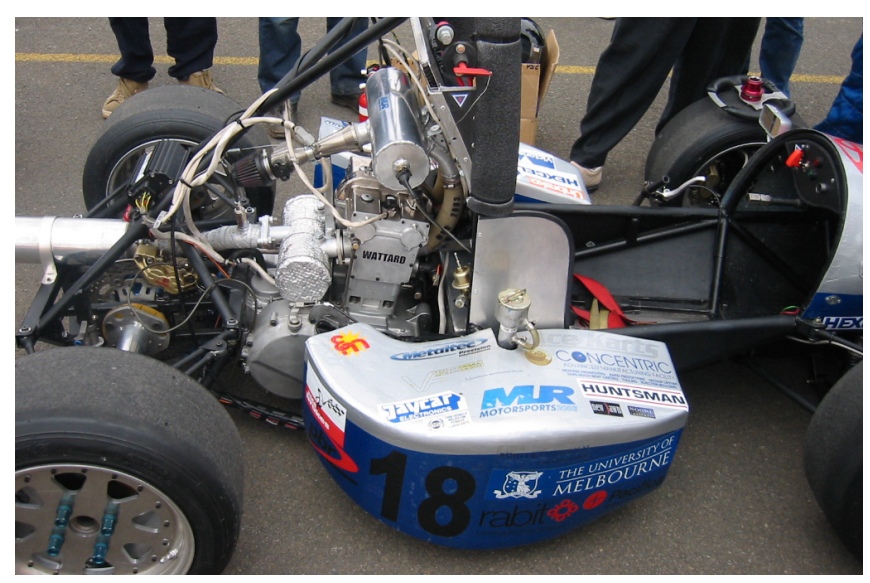

Figure 10: Transient durability testing with the UniMelb 'WATTARD' engine fitted to the MUR-03 Formula SAE vehicle.

\section{LUBRICATION}

The original engine design featured a wet sump lubrication system in order to minimse the parasitic losses associated with driving auxiliary systems such as a dry sump scavenge system. Minimising all parasitic losses was important as this improved brake power. Baffling with scraper plates was assumed to be sufficient in preventing oil surge for the wet sump system, as the Formula vehicle would encounter lateral acceleration forces up to 1.5 G-load $(g)$. However on the vehicle's first outing, initial baffling attempts proved to be unsuccessful with the engine seizing after several minutes operation. Oil surge had resulted in starving both big-end plain bearings of oil, resulting in cylinder two bearing failure and subsequent connecting rod and crankshaft damage, as depicted in Figure 11. The failed components highlight the validity of the calculations and FEM analysis performed during the design stage, with seizure occurring before any internal components were expelled out of the crankcase. The connecting rod beam bending corresponds to the region previously highlighted as having the highest stresses.

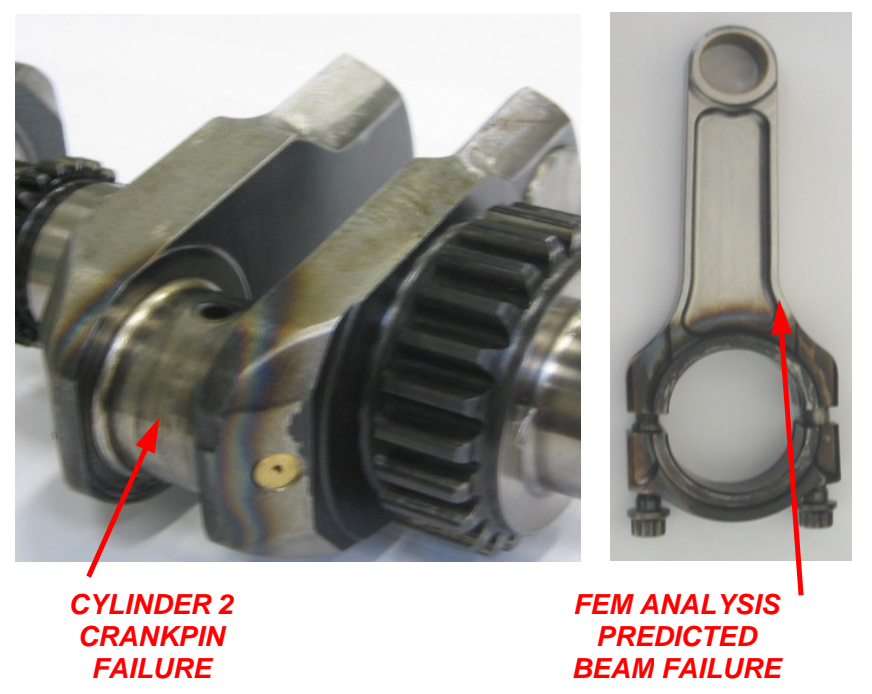

Figure 11: Crankshaft and connecting rod damage as a result of oil surge under high lateral acceleration, leading to big-end bearing failure.
The oil surge problems in the wet sump system were largely associated with the sump pan design. This was flat to allow the engine to be positioned as low as possible to the ground in order to reduce the vehicle's CoG height and thus improve its dynamic performance. Development continued around the wet sump system as there was insufficient time to incorporate a dry sump configuration before competition. Engine development centered on improving the baffling to reduce the oil flowing into the engine's clutch and generator covers under lateral loading.

Trial and error methodology was used to improve the sump baffling in order to reduce oil surge to acceptable limits. Vehicle tests at sustained lateral loading found that insufficient baffling caused instantaneous oil surge, with the oil pressure recovering as the driver reacted to the warning light. As the baffling effectiveness improved pickup oil retention, increased periods of sustained lateral acceleration could be maintained before surge. However with the improved baffling, oil pressure would not instantly recover as the baffling also restricted oil flow back into the sump. The oil surge problems were eventually reduced to acceptable limits with a combination of improved baffling and an increase in oil capacity, which was achieved by overfilling the sump. The final wet sump iteration found that oil pressure could be maintained for 10 seconds at a sustained lateral acceleration of $1.5 \mathrm{~g}$. However, oil pressure would take up to three seconds to recover once surge occurred. This was adequate but not ideal for competition due to the higher parasitic losses and extra mass associated with the increased oil capacity. However, the wet sump solution proved successful, with no oil surge problems at the 2003 competition.

The following year saw the next generation engine design, which featured a dry sump system as depicted in the exploded views of Appendix A. The engine's prototype nature made it difficult to implement an aftermarket system into the design and thus a new system including scavenge pumps was designed and manufactured. The new system incorporated the oil pump and scavenge pump on a common shaft, which was driven internally. Thus the inlet and outlet oil lines were routed through the crankcase to the external oil tank. The tank featured an induced swirl inlet port, to enhance de-airation as no centrifuge was incorporated in the design.

A scavenge ratio sizing of 1.5 (1.5 times the capacity of the pressure pump) was chosen for the scavenge pump. This capacity was dictated by space limitations and was thought to be on the low end as the scavenge pump was required to evacuate oil and blow-by. However, provision had been made in the design to increase the system's shaft speed if the design proved inadequate. The increased shaft speed would also cause oil flow increases and thus an external oil pressure relief valve would need to be implemented. The pump bodies were manufactured in house with OEM supplied G-rotor internals. An internally contoured CNC machined sump 
pan encouraged oil flow to the scavenge pickup. This also allowed the engine to be positioned as low as possible in the vehicle.

Commissioning the new dry sump oil system on the dynamometer indicated that the oil tank level could not be maintained at high speeds or cold conditions. This was caused by the internal oil pressure relief valve, which expelled excess oil into the crankcase in conjunction with insufficient engine scavenging. This problem was overcome by designing and incorporating an external oil pressure relief valve, which returned excess oil directly to the oil tank under its own pressure. A schematic of the oil flow path is given in Figure 12, with more detail also given in Appendix A.

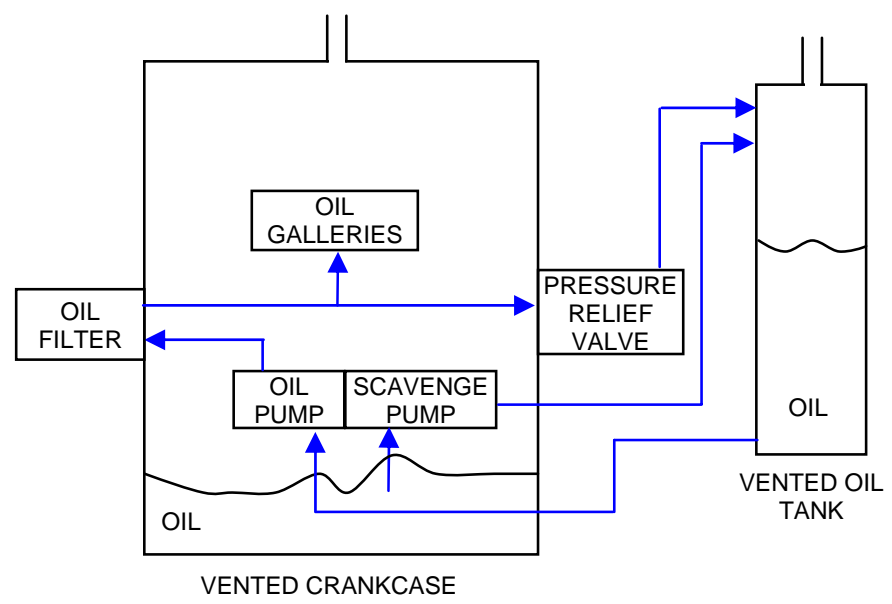

Figure 12: Dry sump oil path schematic, featuring internal oil and scavenge pumps with an external oil pressure relief valve.

It was advantageous to seal the crankcase and allow the scavenge pump to pull a partial vacuum in order to further reduce parasitic losses and increase delivered power $[1,16]$. However, problems existed in maintaining crankcase vacuum under all operating conditions with the revised dry sump system. At some operating conditions, particularly at low load, the crankcase would pressurise and oil would be expelled. This was caused by high blow-by rates associated with insufficient gas loading on the piston ring at low MAP. The blow-by rates were magnified by the first iteration piston design, which featured a single compression ring. The problems associated with crankcase pressurisation were temporality solved by venting the crankcase to the atmosphere in order to continue development.

Figure 13 displays the BMEP in NA operation for both the wet and dry sump systems with correction made to ISO international standards for engine performance [17]. Engine specifications, condition, fuel and ignition settings were held constant over both runs. The effect of driving the dry sump scavenge pump can be seen with reduced BMEP over all speeds. Power losses are calculated via the differing performance, with the dry sump system absorbing increases in power as the engine speed increased.

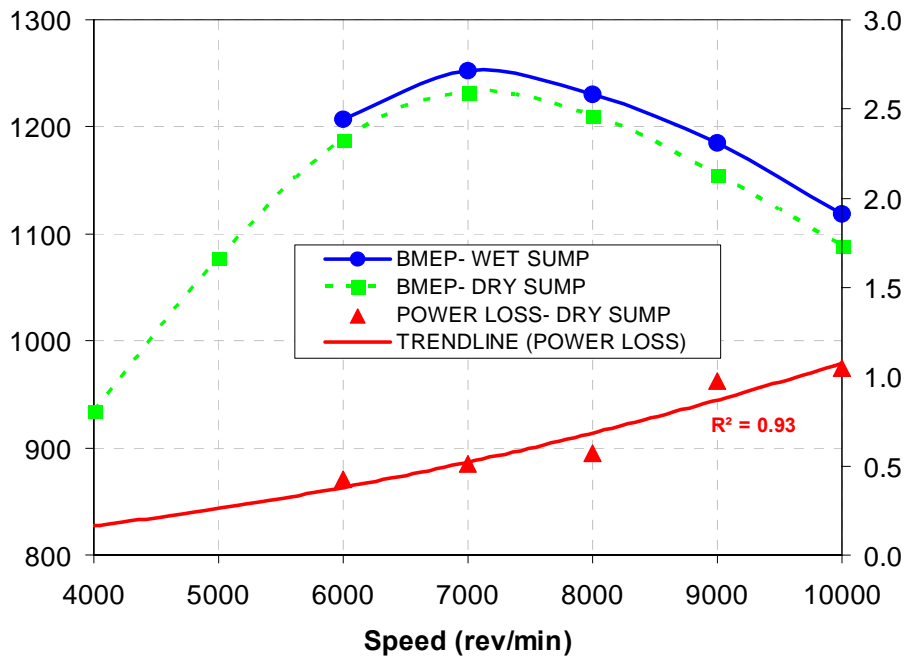

Figure 13: Brake performance effects for both wet and dry sump lubrication systems.

This performance lost was originally thought to be partially recovered by evacuating the crankcase as previously described. However, with insufficient scavenge due to the inadequate dry sump system, an externally driven scavenge pump was used to draw a minimum of $50 \mathrm{kPa}$ crankcase absolute pressure (CAP) over all speeds at WOT. Back to back constant speed dynamometer testing showed no change in brake performance with varying CAP, with results lying within the bounds of the $1 \%$ measurement error. Because no clear performance gains were observed with the crankcase under vacuum, it remained vented for dry sump operation, performing successfully at the 2004 Australasian competition. However, dynamometer transient testing may have yielded differing results, as engine acceleration rates are expected to be improved under vacuum conditions.

\section{TUNING - FUEL INJECTOR LOCATION}

PFI engine development initially commenced on the dynamometer with each cylinder's fuel injector positioned high in the intake runner (setup 1), as shown in Figure 14. This has published brake output advantages due to intake charge cooling affects associated with vaporising the liquid fuel $[1,16]$. This charge cooling is caused by the evaporation of the liquid gasoline due to latent heat provided by the manifold walls and incoming air. This can reduce intake charge temperatures by as much as $22^{\circ} \mathrm{C}$, depending on the mixture strength, thus increasing air density and $\eta_{\mathrm{VOL}}$ [18]. NA dynamometer testing confirmed a 2-3\% increase in brake output at WOT when compared to the low injector setup, also shown in Figure 14. This intake charge cooling affect was also observed under some ambient conditions with ice forming on the lower part of the intake runner, which was manufactured using Selective Laser Sintering (SLS). A Nylon-66 material was used in the SLS process as it minimised the heat flow from the cylinder head into the intake manifold. 


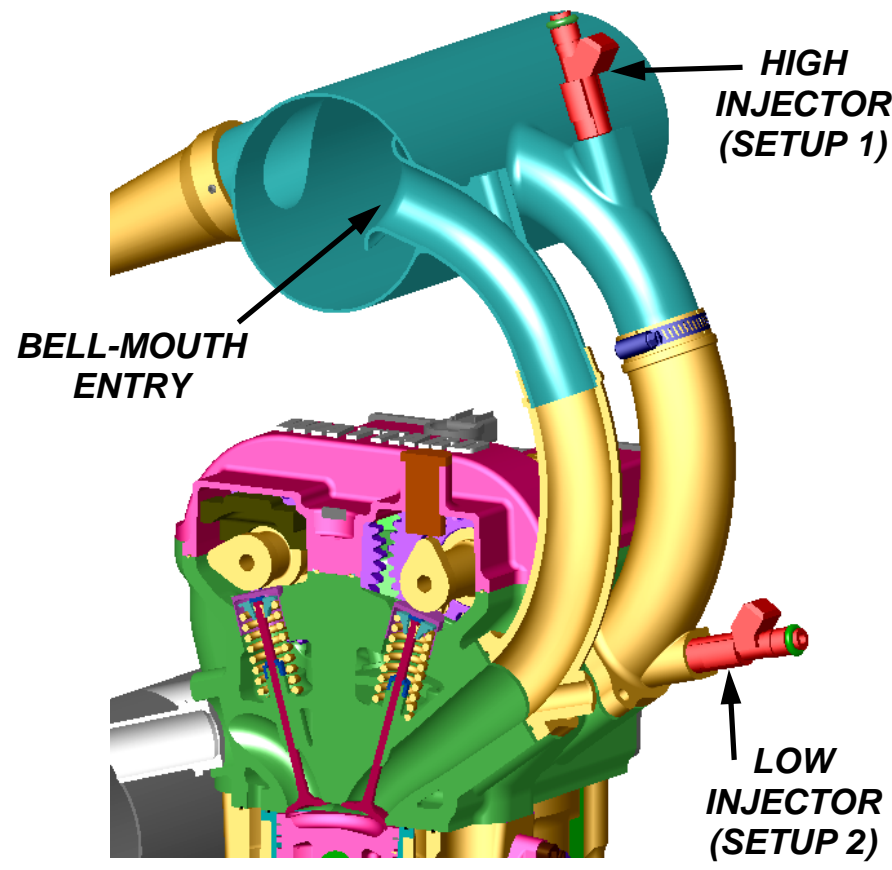

Figure 14: Intake manifold section highlighting the two differing injector setup positions used during development

The two injector locations resulted in different EMS fuel calibrations, with high individual cylinder trimming needed to accommodate the high injector setup. This was caused by the unequal fuel distribution, as the high injector setup was more prone to fuel back flow into the plenum due to intake resonant waves. This affect was further magnified with the unequal firing order, with the second cylinder's induction offset by $180^{\circ}$ crank angle (CA). Injection timing also needed adjustment between both setups to compensate for the charge transport delays due to the differing mixing lengths. MBT-injection timing methodology, as previously defined in the tuning strategy, was used to optimise both setups.

Vehicle testing commenced with the high injector setup. Initial testing found poor transient response, with lags between throttle tip-in and engine power increase. Transient calibration had previously not been optimised due to dynamometer fixed speed limitations. This calibration was intended to be performed using feedback information from the driver, while running a variety of vehicle tests. Transient calibration was restricted by the MOTEC ECM, which allowed only a fixed accelerator enrichment value to be adjusted. Maximum enrichment was limited to a $100 \%$ increase, based on the fuel main table by the ECM software.

The logged data from vehicle testing revealed MAP followed TP, indicating increased airflow. However the engine speed did not instantaneously respond as the recorded fuel mixtures showed a lack of compensation for the sudden increase in airflow. Mixtures initially went lean and then rich, with the wide band heated exhaust gas oxygen (HEGO) sensor limiting mixture logging between lambda $(\lambda) 0.8$ and 1.2, as shown in Figure 15.
The fuel mixture inconsistencies were only evident on sudden accelerator tip in and caused by the long mixing length associated with the high injector position. This gave the fuel a chance to return to liquid form after initial vaporisation, aided by the cold surfaces of the SLS intake runners. The fuel breakout would cause wall wetting and/or pooling along the length of the intake runner, thus making it difficult to accurately control fuel mixtures.

Attempts were made to minimise these affects, with full accelerator enrichment used to avoid the lean region. However this was unsuccessful, resulting in only richer regions once the fuel eventually found its way into the cylinder. Ignition advance was adjusted at part open throttle (POT) in an attempt to introduce more heat into the system to aid in fuel vaporisation, but had little effect. Thus the high injector setup was discarded.

A combination high and low injector strategy may have been implemented but was dismissed due to the increased system complexity and time limitations. In addition, the system would only be beneficial at less than choked flow operating conditions. If the system was implemented, high injectors would only be used at consistent WOT operation, which improved brake power output. The low setup would be used at all other operating conditions to avoid wall wetting problems and improve efficiency.

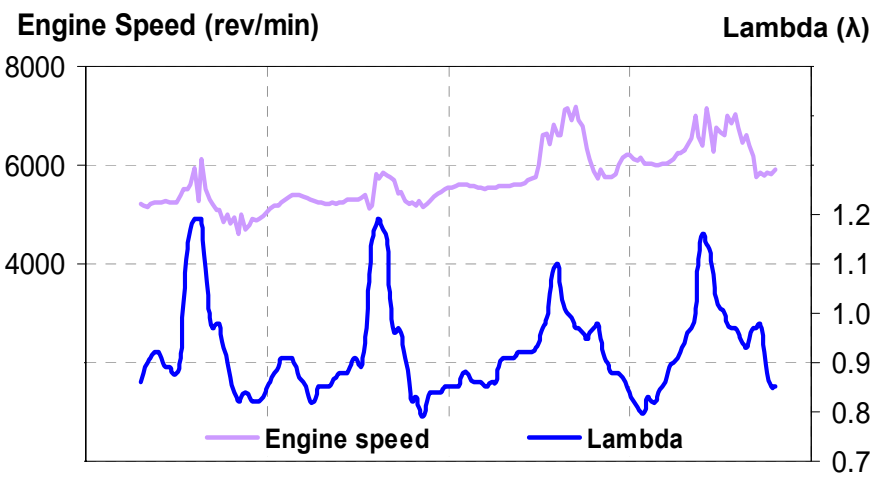

Throttle Position (\%) MAP (kPa)

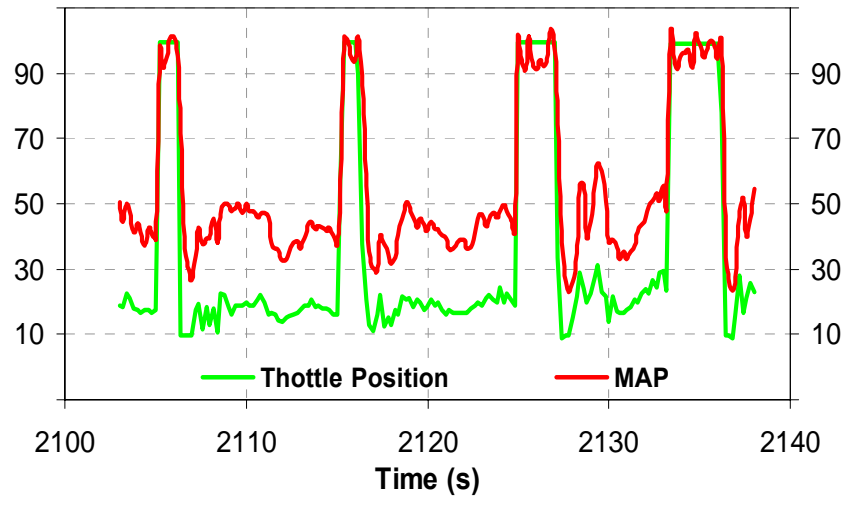

Figure 15: Fuel mixtures at associated MAP, TP and engine speed during transient vehicle testing for the high injector setup depicted in Figure 14. Note the fuel mixture excursion from lean to rich on accelerator tip in, caused by fuel wall wetting due to the long mixing length. 
High injector setups are common in motorsport applications [16]. However, the reasoning behind the unsuccessful implementation in this application involves the upstream throttle location and long curved intake runners, tuned for lower speeds. Downstream throttling which is featured in the majority of specific racing engines aids in improving transient response. Other advantages include improved fuel breakup and mixing at reduced throttle openings due to the higher local velocities associated with the reduced throttled area [19].

\section{TUNING - INTAKE RUNNER LENGTH}

Optimising the length of the intake runner in order to take advantage of resonant wave tuning has been well documented in the literature $[16,18,19]$. This resonant wave, when correctly timed in the induction process, improves air consumption and cylinder trapping while reducing the exhaust residual gas content within the cylinder [20]. Resonant wave instantaneous pressures in the order of $180 \mathrm{kPa}$ absolute have previously been documented in high BMEP NA racing engines [21]. Results from NA experimental testing suggest that for a given MAP, above $80 \mathrm{kPa}$, air consumption rates are highly dependent on resonant wave tuning, with the pressure waves increasing in intensity to become most dominant at WOT [3].

In boosted applications, resonant tuning is generally less important since the engine airflow can be increased using the compressor. The higher intake pressures naturally cause through scavenging during valve overlap to reduce the residual gas content. However, resonant tuning can be used to help improve air consumption at engine speeds where boost levels are limited by compressor delivery rates, especially at lower engine speeds in TC applications.

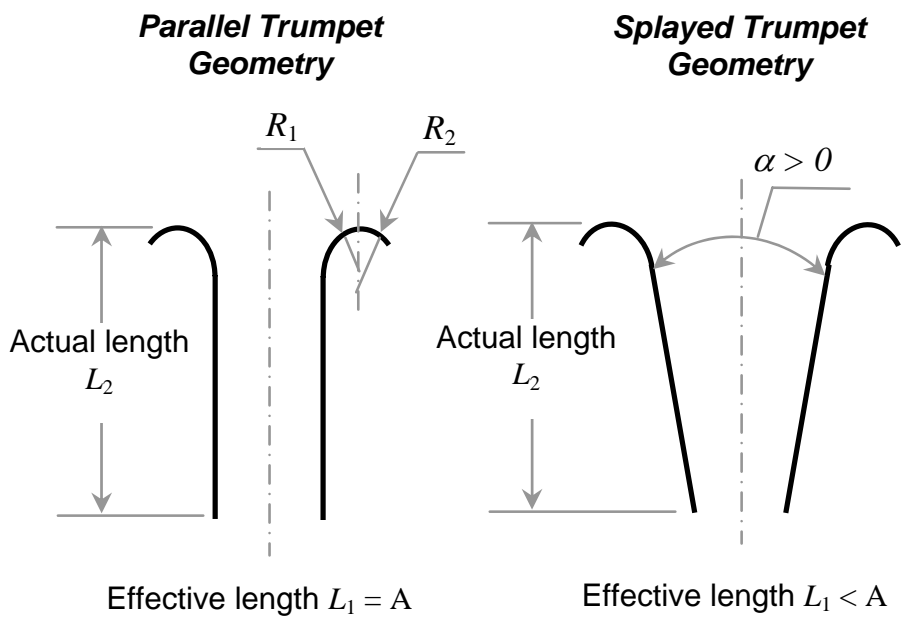

Figure 16: Varying trumpet geometry highlighting the actual and effective length, governed by the defined trumpet parameters.
Experimentation with varying trumpet geometry in NA operation found that resonant wave tuning is highly dependent on the effective tract length $\left(L_{1}\right)$ coupled with valve timing events. The effective length differs slightly from the actual length $\left(L_{2}\right)$ as defined in Figure 16. The actual length is defined as the centerline distance from the intake valve to the highest trumpet edge. However, varying tract geometry involving the inner bell-mouth radius $\left(R_{1}\right)$ and the splayed angle $(\alpha)$ can cause minor changes to the effective length, while the actual length remains unchanged. These changes in performance were found to be minor due to the low tuning speeds, making the engine fairly insensitive to trumpet geometry changes.

Airflow bench testing and physical experimentation found that it was advantageous to have a bell-mouth trumpet entry into the runner to minimise flow losses. Particular attention was focused on the inner $\left(R_{1}\right)$ and outer $\left(R_{2}\right)$ bell-mouth radius geometry, with results showing that the outer radius geometry had no effect on performance.
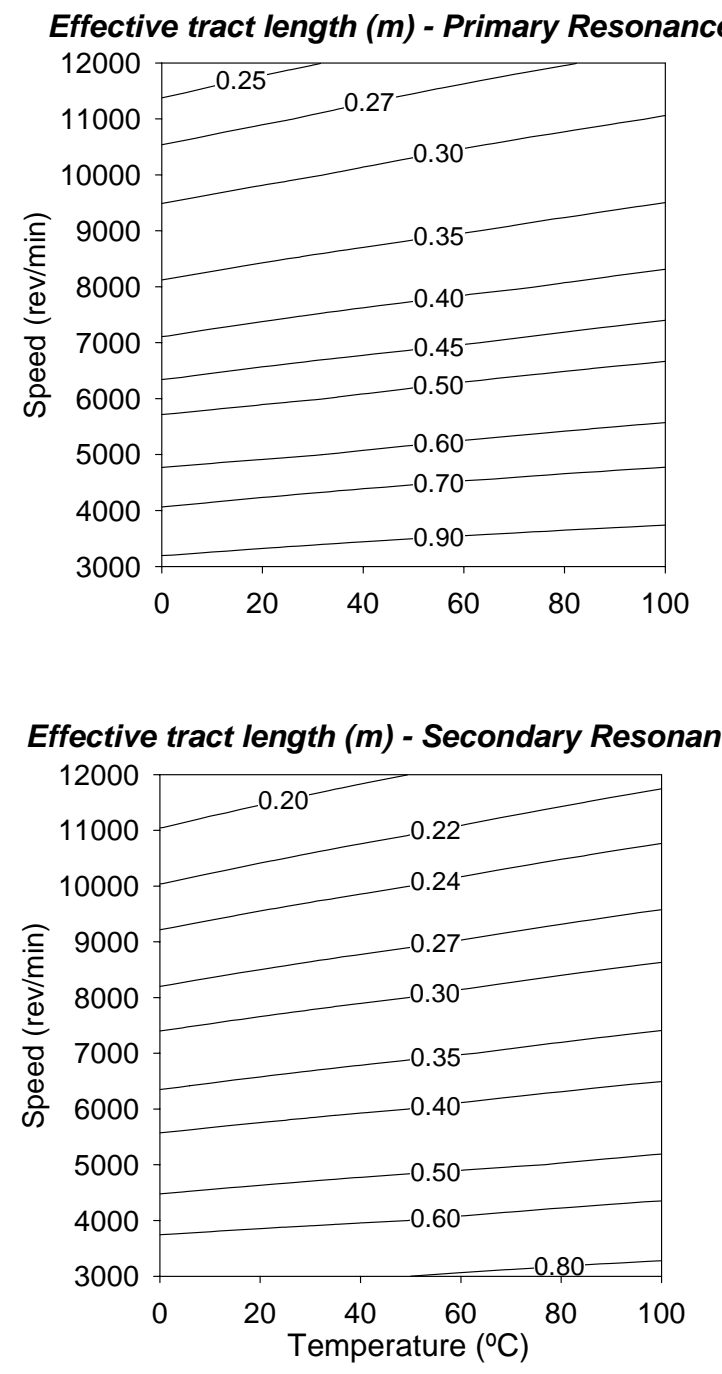

Figure 17: Effective inlet tract lengths highlighting the tuned speed for peak primary and secondary resonance with varying temperature effects. 
Figure 17 displays the effective tract length and corresponding engine speed for the primary and secondary resonance. The plots were created from a theoretical model developed by the first author, with experimental results used for model validation. It is noted that the results only apply to the present engine configuration, they however may serve as a guide to determine the tuned effective tract lengths for other applications. Gas temperature affects associated with ambient conditions and injector location result in speed of sound changes, which affect wave propagation rates and thus tuned lengths. The primary resonance, associated with peak resonant tuning corresponds to three residual waves forming per engine cycle. The secondary resonance corresponds to four residual waves per cycle and is not as dominant [21].

\section{TUNING - ODD FIRE EFFECTS}

Figure 18 displays the individual cylinder $\eta_{\text {VoL }}$ versus engine speed for carburetted and PFI NA modes with differing induction systems. It is evident that the carburetted mode has negligible $\eta_{\mathrm{VOL}}$ variation between cylinders, as the system featured individual carburettors and trumpets open to the atmosphere. This setup allowed each cylinder to operate independently of each other with no air consumption limitations. Results from the PFI system show an overall reduction in $\eta_{\mathrm{VO}}$ when compared to the carburetted mode over all speeds. Also evident is the $\eta_{\text {VOL }}$ reduction in the second cylinder, with recorded differences as high as $10 \%$. These PFI air consumption discrepancies are primarily caused by implementing the mandatory intake restriction and corresponding plenum chamber.

\section{Cylinder $\eta_{\text {VOL }}(\%)$}

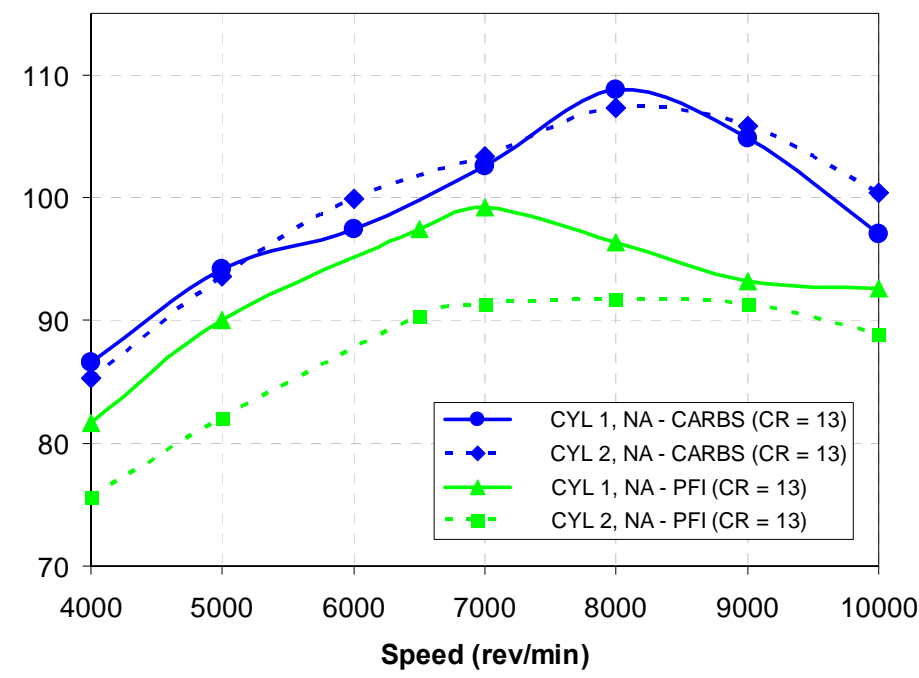

Figure 18: Cylinder $\eta_{\mathrm{VOL}}$ comparisons at WOT for the carbureted and PFI NA modes, highlighting the losses associated with the PFI intake restriction and the odd fire pulsing.

The PFI air consumption rates in NA operation were not high enough to cause restrictor choking. However, the intermittent pulsing attributed to the odd firing order limited instantaneous peak airflow through the nozzle, resulting in the plenum chamber being partially scavenged. This effect increases with engine speed, resulting in further reductions in performance. To smooth out the large flow fluctuations through the restrictor, larger volumes downstream are needed, thus compromising transient response $[1,3]$.

The odd firing order effect also contributed to the second cylinder having reduced airflow, due to the plenum being partially evacuated by the previous induction. With the induction between the first and second cylinders spaced by $180^{\circ} \mathrm{CA}$, there was insufficient time for recovery, resulting in an uneven air distribution between cylinders. This resulted in cylinder variations in $\eta_{\mathrm{VOL}}$ and trapped residual gas fraction, as confirmed by each cylinder's exhaust gas analysis. Thus, individual cylinder fueling requirements were needed to equalise AFR, with up to a $10 \%$ trim needed for the second cylinder at WOT. This charge robbing effect could be minismised with improvements in intake manifold design. However, the plenum chamber geometry had been optimised for TC operation.

The airflow reductions in the NA PFI mode associated with the intermittent pulsing through the intake restriction and cylinder charge robbing are significantly reduced in the TC mode, as the engine is force fed air via the compressor. This minimises the pulsing effect caused by the piston motion during induction, with the compressor constantly inducing the maximum mass flow through the orifice.

Exhaust manifold design was heavily influenced by the unequal pulse effects attributed to the uneven firing order of this engine. The unequal pulsing caused problems ranging from exhaust turbine velocity fluctuations to ineffective cylinder scavenging, which limited achievable boost pressures. The ineffective cylinder scavenging resulted in high residual gas fractions, which decreased performance and increased knock tendency.

To investigate this effect, several exhaust manifold concepts were proposed. The first implemented pulse type turbocharging, with unequal exhaust primary lengths to compensate for the odd pulsing. Pulse type turbocharging is beneficial, as it has advantages associated with reducing turbocharger spool time and delivering higher pressure ratios [14,22]. However, this design had limitations in that the exhaust lengths were speed dependent and thus the system could only be tuned to eliminate odd pulsing at a given speed. Constant pressure turbocharging, featuring an exhaust plenum chamber, was also investigated as it smoothed the flow into the exhaust turbine. However, the increased manifold surface area increases the heat losses and reduces turbocharger delivered enthalpy. The exhaust manifold geometry was optimised for both systems with the help of WAVE ${ }^{\circledR}$, with simulation results shown in Figure 19. 


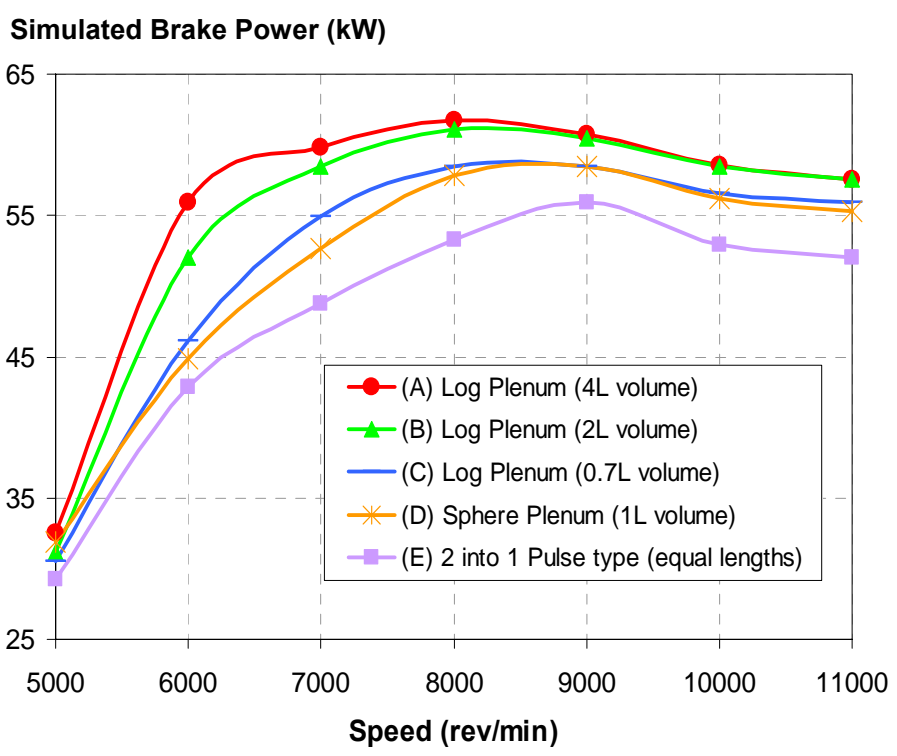

Figure 19: Simulated results with constant pressure and pulse type turbocharging.

Results from Figure 19 show significant brake power improvements when employing constant pressure type turbocharging to this particular odd firing engine. The reduced performance of the equal length pulse type setup is evident across all speeds, as the increased residual gas content reduces air consumption. Performance increases are associated with increasing the exhaust manifold volume, as this reduces the pulsing effect, thus reducing the exhaust turbine velocity fluctuations and increasing delivered boost. This effect is most dominant at lower engine speeds, prior to the intake restriction limiting airflow. The odd pulsing effects decrease with increasing engine speed, due to the reduced time intervals. From the simulation results, an exhaust manifold geometry with a volume of four liters was selected. Larger volumes provide small gains in output but are coupled with increased heat losses and transport times and thus were not used.
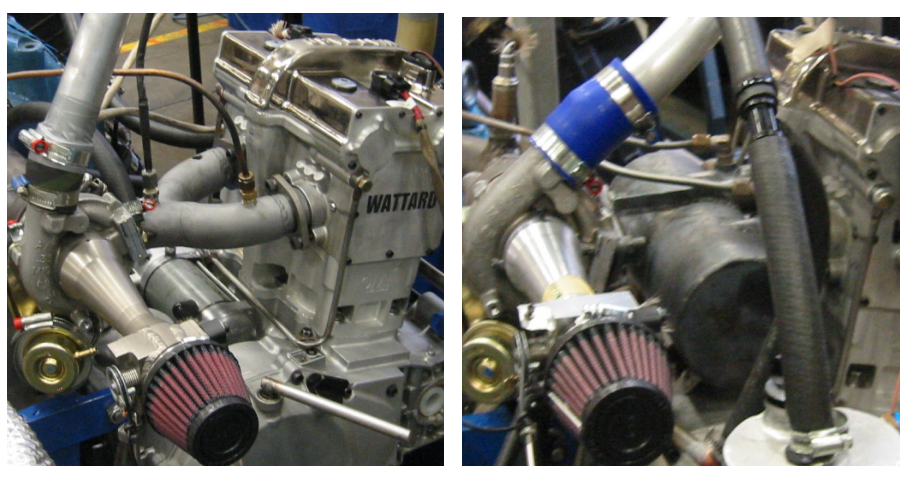

Figure 20: Varying exhaust manifold geometry, (left) two into one pulse system (model E), (right) Watson's KEC plenum system (model A) optimised through WAVE ${ }^{\circledR}$.

The most efficient plenum geometry was thought to be a sphere, as this has the minimum surface area to volume ratio, reducing heat losses. However, simulation results showed that the log style plenum had reduced flow losses for similar volumes and so was employed. The log style plenum also permitted the adoption of Watson's KEC rolling flow design, which had been used successfully in intake manifolds $[1,2,5]$, but as yet had not been implemented to exhaust manifold designs.

Figure 20 displays both exhaust manifold designs used during testing. Development commenced with the exhaust plenum design. However, as a result of thermal cracking, the plenum was replaced during development in favor of the simple two into one pulse manifold. With this manifold design, engine torque was reduced by as much as $20 \%$, with severe knock problems at previously determined MBT-spark timing values. In order to avoid the DL for the given CR, boost levels were reduced and thus performance suffered, with results shown in Figure 21. To improve engine performance and reliability, the initial plenum design was further developed to prevent thermal cracking and was later implemented. This was achieved by changing the material specification from 316 stainless steel to a low carbon mild steel and by increasing the manifold wall thickness.

BMEP (kPa)

Spark Timing (deg. BTDC)

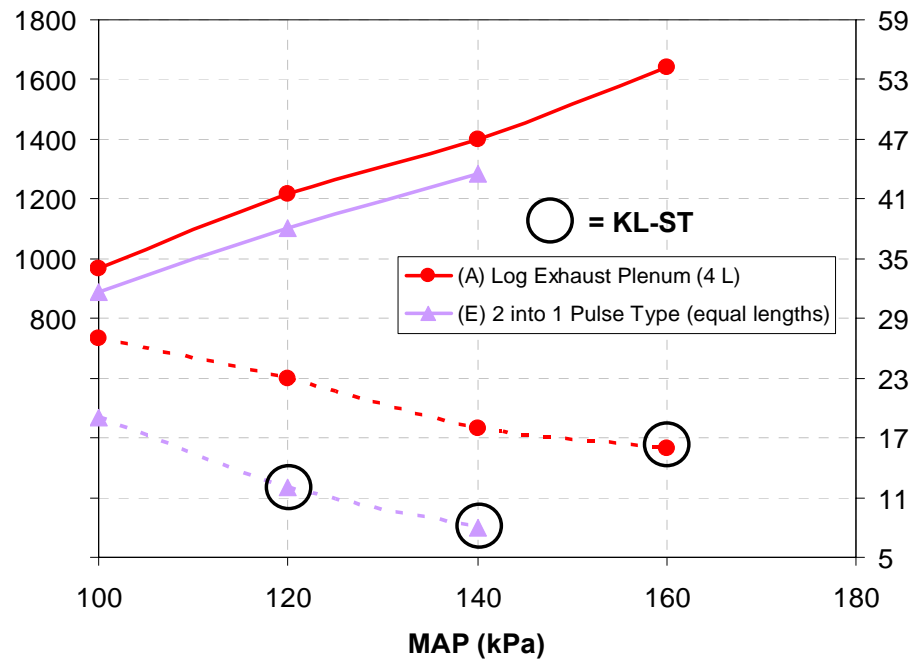

Figure 21: BMEP and spark timing versus MAP for constant pressure and pulse type turbocharging. Experimental results highlight the reduced performance of the two into one pulse type system (model E). $5000 \mathrm{rev} / \mathrm{min}, 10: 1 \mathrm{CR}$.

\section{TUNING - KNOCK}

Testing found that for a given CR and MAP condition, the engine is less prone to knock at high speeds $[3,23]$. This is a consequence of the increased flame speed within the combustion chamber, which increases the rate of consumption of the unburnt mixture in the end-gas region. It is also interesting to note that spark retard and/or fuel enrichment can be used as a method of knock control for up to 1-2 CR points, depending on the knock severity. This can be a useful tool during boosted engine development, as it allows the calibrator some margin to avoid the $\mathrm{DL}$ without having to reduce the $\mathrm{CR}$. 
However, CR reduction from 13 to 10 was eventually needed to reduce knock intensity to acceptable limits to achieve the design objectives.

Figure 22 displays the cylinder pressure for a heavy knocking cycle, with the knock amplitude well above the previously defined DL. Running at this limit has well published associated problems, ranging from component surface erosion to failure depending on the knock location and severity. The literature and experiments have shown that some commonly damaged components include pistons, cylinder bores and liners, piston rings, cylinder head gaskets, big end bearings and spark plugs $[19,23,24]$.
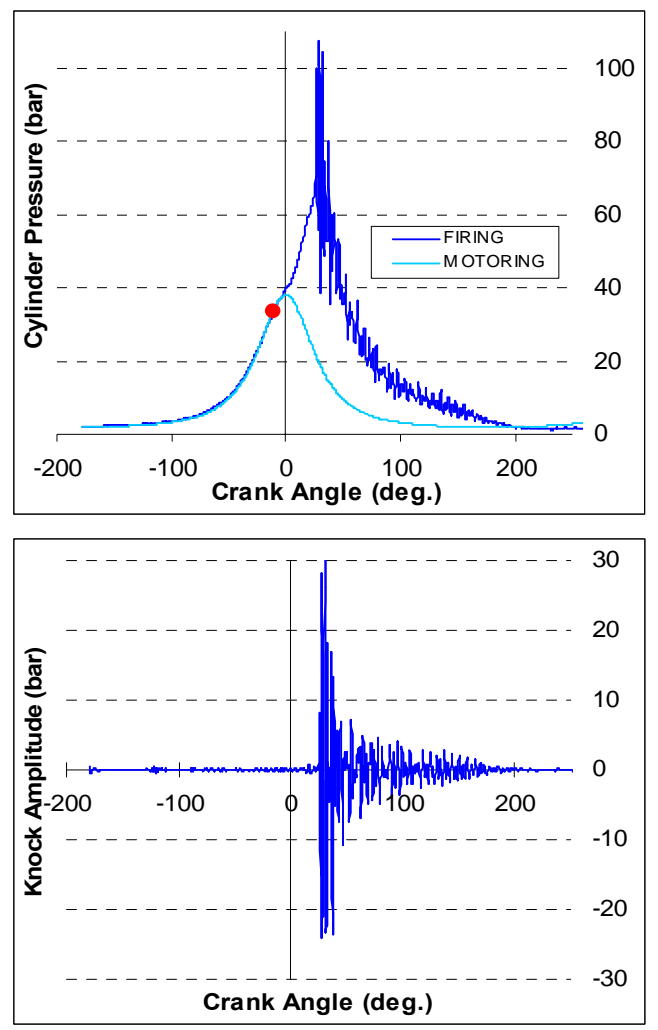

Figure 22: A recorded heavy knocking cylinder pressure cycle, highly TC, $7000 \mathrm{rev} / \mathrm{min}, 11: 1 \mathrm{CR}, 220 \mathrm{kPa}$ MAP

Engine development commenced with no form of knock detection due to difficulty in physically locating a cylinder pressure transducer in the pent roof combustion chamber. As an alternative, the engine operator was relied upon to audibly discern the knock severity. This proved to be troublesome as depicted in Figure 23, with several top land piston failures occurring early in development. With the engine featuring a gasketless interface, knock above the DL would quickly result in piston failure due to the absence of gasket weakspot [12].

After several piston failures, a Kistler 601-B1 cylinder pressure transducer was installed according to Kistler remote mounting instructions. However, non-flush mounting caused excessive resonance within the connecting passage and clearance chamber, producing high noise signals. This was overcome by flush mounting and coating the transducer with high temperature RTV silicon to avoid thermal shock $[1,25]$. This significantly reduced development time, as any form of knock could be detected and avoided before piston land failure. It is also interesting to note that the audible noise associated with the heavy knocking condition was closer to a high frequency crackle at the elevated engine speeds, quite different to knock in conventional engines.

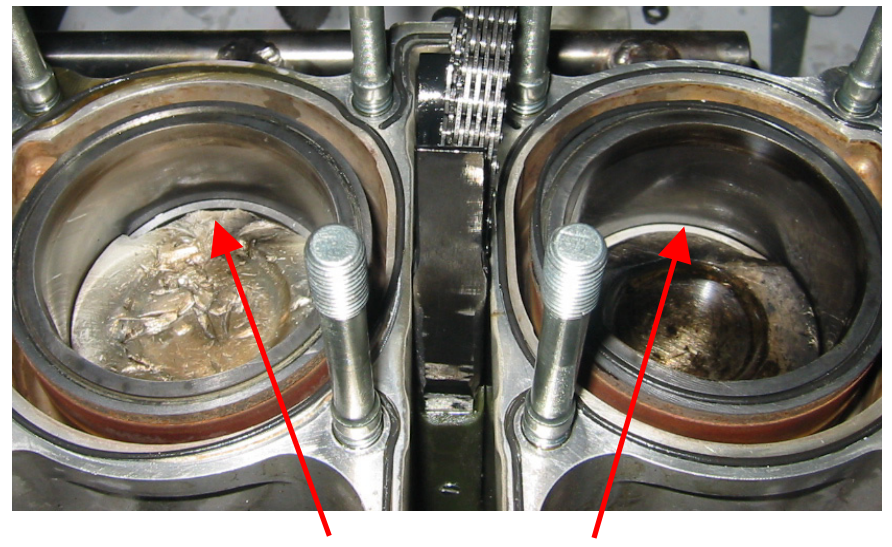

INLET SIDE PISTON LAND FAILURE

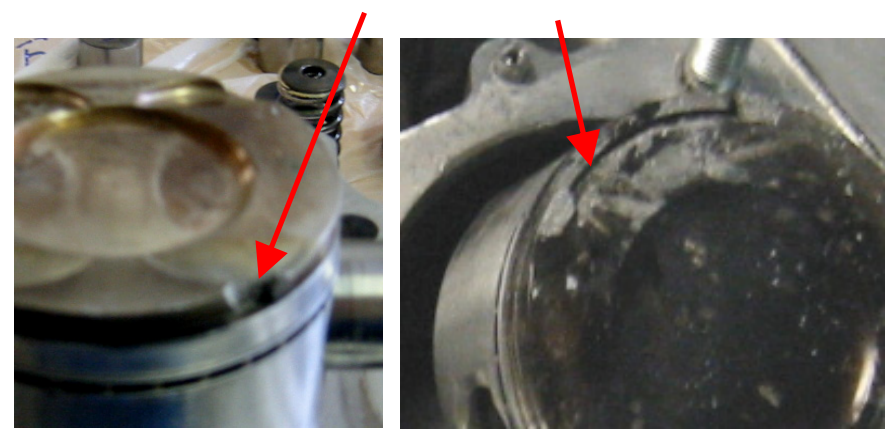

Figure 23: Adverse effects of heavy knock in the end-gas region above the DL. (upper): Simultaneous inlet side piston land failure in both cylinders. (lower): Further inlet side failures after increased piston oil cooling, directed towards the piston intake underside.

\section{RESULTS AND COMPARISONS}

Figure 24 displays a comparison of BMEP for a range of recently tested engines. A peak WATTARD TC value of 25 bar was observed and is believed to be the highest specific output recorded for small engines operating on pump gasoline [3], surpassing the 22 bar from GM's 2.0$L$ TC Ecotec engine [26]. The relatively high BMEP of the NA modes indicates excellent port design and high mechanical efficiency, which produces higher BMEP values when compared to engines normally used in this Formula [1,2]. Additional improvements in NA operation are expected due to the valve timing and exhaust manifold geometry which had been optimised for turbocharging. 


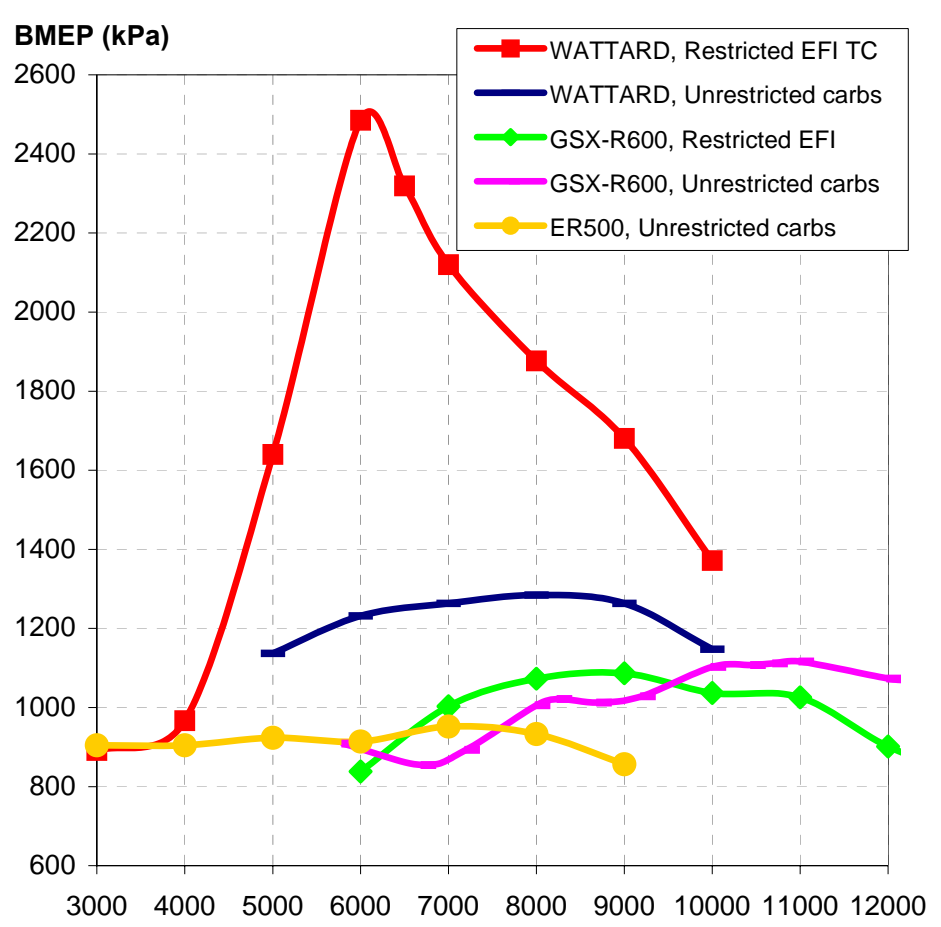

Engine Speed (rev/min)

Figure 24: BMEP of the 'WATTARD' TC engine at sonic flow conditions above $6000 \mathrm{rev} / \mathrm{min}$ compared with the NA version of the engine and the team's previous engines.

Figure 25 demonstrates the engine's ability to deliver almost constant power over the 6000-10000 rev/min speed range in the TC mode. At $6000 \mathrm{rev} / \mathrm{min}$ and 270 $\mathrm{kPa}$ MAP, the engine's peak torque is 2.5 times that of the NA - PFI version. Over this speed, the torque falls as the power is limited by sonic flow through the restriction. Figure 25 also compares the simulated results with the TC performance data. The agreement between the two is excellent, thus highlighting the success of the simulations.

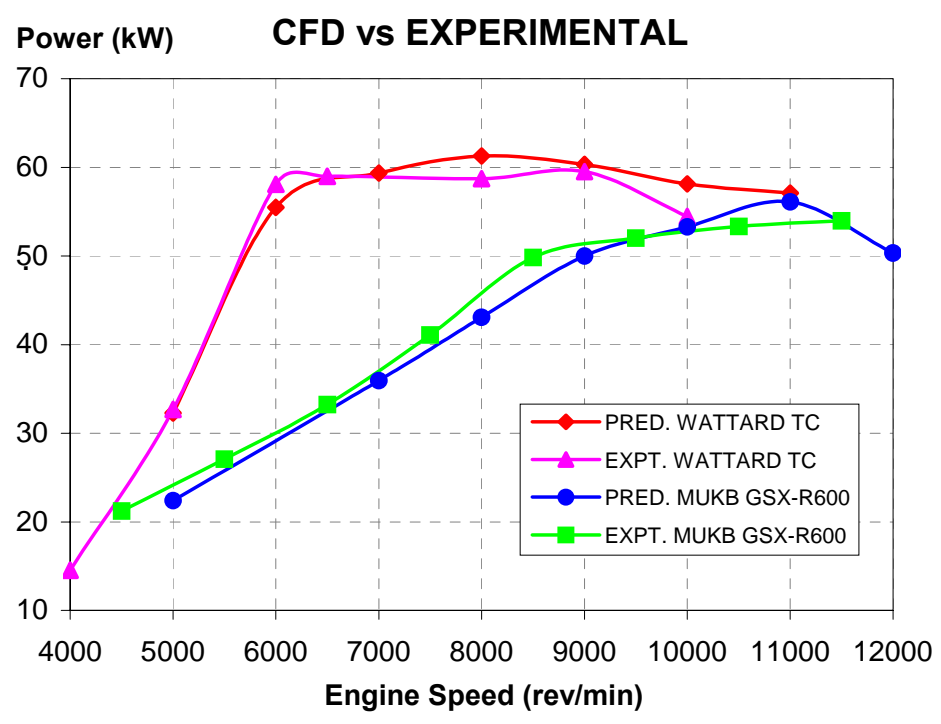

Figure 25: Comparison of experimental and predicted engine performance for both the 'WATTARD' and GSX-R600 engines.

\section{CONCLUSIONS}

The mechanical component design, lubrication, tuning and control aspects of a restricted intake, odd fire, highly TC engine for Formula SAE competition has been described. The engine was specifically designed and configured for the purpose, being a twin cylinder in-line arrangement with double overhead camshafts and four valves per cylinder.

Detailed theoretical analysis was used to determine engine specifications and operating conditions, thus necessitating the need for a new engine design as a result of operating in the highly TC mode. The design centered around the theoretical analysis performed, with the importance of using CAE applications together with calculations and modeling highlighted by the successes and failures of the project.

The TC development methodology has been outlined together with the importance of simulation as an aid in accelerating engine development. These tools have enabled improved performance and understanding at reduced costs and lead times. Excellent agreement between actual and simulated brake performance highlighted the success of the simulations.

Challenges faced in this engine design involved the successful implementation of a dry sump lubrication system, needed to overcome oil surge problems found with the initial wet sump engine during vehicle testing. The associated performance and characteristics of the two systems are documented. Tuning effects, including injector location and intake manifold geometry were investigated on the dynamometer and in vehicle testing, with performance and transient response issues highlighted.

Odd firing and intake restrictor effects on air consumption are also highlighted for both the NA and TC modes. These effects on turbocharger implementation are investigated with both pulse and constant pressure type systems used during development. Results from simulation and experimentation show significant brake power improvements when employing constant pressure type turbocharging to this particular odd firing engine.

End-gas knock has been highlighted as being the single most important limiting factor in tuning highly TC engines. Testing demonstrated that spark retard and/or fuel enrichment can be used as a method of knock control for up to 1-2 CR points depending on the knock severity. Knock severity was also found to decrease with increasing engine speeds and decreasing end-gas volumes, thus enabling increased $\mathrm{CR}$ and/or MAP before exceeding the DL.

This downsized engine package and employed tuning strategy resulted in the Formula vehicle being very competitive in competition, achieving exceptional fuel economy while maintaining excellent power and 
drivability. The engine was installed into successive MUR Motorsport vehicles in 2003 and 2004 and became the first prototype engine to successfully compete in the competition's 25 year history. The engine and car were very competitive, finishing first in the fuel economy event at the 2004 competition. Peak BMEP values of 25 bar were also achieved at mid range speeds, believed to be the highest recorded for small engines on pump gasoline. Near constant power could also be achieved over half the speed range in the highly TC mode.

\section{ACKNOWLEDGMENTS}

My personal thanks go to my family and friends for their continual support of this project. Thanks are due to Professor Harry Watson, Steven Konidaris and Mohammad Ali Khan for their persistence and guidance during the most trying times of the engine development phase. The team is also grateful, to all academic, postgraduate and technical staff involved in the project.

To the generous sponsors that made the UniMelb 'WATTARD' engine possible, we offer our sincere thanks for supporting the excellent learning activity at the University of Melbourne.

$>$ ACL Bearing Company -
$>$ APEP Pistons -
$>$ Argo Engineering -
$>$ Bishop Innovation -
$>$ Bohler Uddeholm -
$>$ CadCore Pty Ltd -
$>$ Concentric Asia Pacific -
$>$ Cosway Motorcycles -
$>$ Davies Craig -
$>$ Electromold -
$>$ Farley Laserlab -
$>$ Garrett Honeywell -
$>$ Kawasaki Australia -
$>$ Magnesium Technologies -
$>$ MAME Centre for Manufacturing -
$>$ Men Ignitions -
$>$ QMI Solutions -
$>$ Ricardo -
$>$ Robert Bosch -
$>$ Siemans VDO -
$>$ Southside Cylinder Heads -
$>$ University of Melbourne -
$>$ Wade Camshafts -
Whitehorse Industries -

Tas, Australia

Vic, Australia

NSW, Australia

NSW, Australia

Vic, Australia

Vic, Australia

SA, Australia

Vic, Australia

Vic, Australia

Vic, Australia

Vic, Australia

NSW, Australia

NSW, Australia

Vic, Australia

Vic, Australia

NSW, Australia

Vic, Australia

Qld, Australia

Sussex, UK

Vic, Australia

Vic, Australia

Vic, Australia

Vic, Australia

Vic, Australia

Vic, Australia

\section{NOMENCLATURE}

$\begin{array}{ll}\text { AFR } & \text { air fuel ratio } \\ \text { BMEP } & \text { brake mean effective pressure } \\ \text { CA } & \text { crank angle } \\ \text { CAD } & \text { computer aided design } \\ \text { CAP } & \text { crankcase absolute pressure } \\ \text { CNC } & \text { computer numerically controlled } \\ \text { CoG } & \text { center of gravity } \\ \text { CR } & \text { compression ratio } \\ \text { DL } & \text { damage limit } \\ \text { DOHC } & \text { double over head camshafts } \\ \text { EMS } & \text { engine management system } \\ \text { EVC } & \text { exhaust valve closed } \\ \text { EVO } & \text { exhaust valve open } \\ \text { FEM } & \text { finite element method } \\ \text { g } & \text { G-load } \\ \text { HEGO } & \text { heated exhaust gas oxygen } \\ \text { HC } & \text { hydrocarbon } \\ \text { IVC } & \text { inlet valve closed } \\ \text { IVO } & \text { inlet vale open } \\ \text { KA } & \text { knock amplitude } \\ \text { KEC } & \text { kinetic energy conservation } \\ \text { KL } & \text { knock limit } \\ \text { MAP } & \text { manifold absolute pressure } \\ \text { MBT } & \text { maximum brake torque } \\ \text { MUR } & \text { Melbourne University Racing } \\ \text { NA } & \text { normally aspirated } \\ \text { NDIR } & \text { non dispersive infra red } \\ \text { PFI } & \text { port fuel injection } \\ \text { POT } & \text { part open throttle } \\ \text { SC } & \text { supercharged } \\ \text { SLS } & \text { Selective Laser Sintering } \\ \text { ST } & \text { spark timing } \\ \text { TC } & \text { turbocharged } \\ \text { TP } & \text { throttle position } \\ \text { WOT } & \text { wide open throttle } \\ \eta \text { VOL } & \text { volumetric efficiency } \\ \lambda & \text { lambda } \\ & \end{array}$

\section{CONTACT}

Prof. Harry Watson

Head Thermofluids Group

Department of Mechanical Engineering

University of Melbourne

Victoria, Australia, 3010

Email: harrycw@unimelb.edu.au

William Attard

Thermofluids Group

Department of Mechanical Engineering

University of Melbourne,

Victoria, Australia, 3010

Email: william_attard@hotmail.com 


\section{REFERENCES}

1. ATTARD, W., 'Design, Performance and Analysis of a Downsized Highly Turbocharged $0.45 \mathrm{~L}$ Formula SAE Engine', Current Ph.D. Thesis, Mech. Eng. Dept., Univ. of Melbourne. (2006)

2. ATTARD, W. and WATSON, H.C., 'Development of a 430cc Constant Power Engine for FSAE Competition', SAE paper 2006-01-0745. (2006)

3. ATTARD, W., WATSON, H.C., KONIDARIS, S. and KHAN, M., 'Comparing the Performance and Limitations of a Downsized Formula SAE engine in Normally Aspirated, Supercharged and Turbocharged Modes', SAE paper 2006-32-0072. (2006)

4. MILIKEN, W.F. and MILIKEN, D.L., 'Race Car Vehicle Dynamics', ISBN 1-56091-526-9. (2005)

5. KARAGOUNIS, T. and STRAUS, 'Development of a 90 bhp Turbocharged Engine for use in Formula SAE-A', Undergraduate Thesis, Mech.Eng. Dept, Univ. of Melbourne. (2002)

6. LAKE, T., STOKES, J., MURPHY, R., OSBORNE, R. and SCHAMEL, A., 'Turbocharging Concepts for Downsized DI Gasoline Engines', SAE paper 200401-0036. (2004)

7. LECOINTE, B. and MONNIER, G., 'Downsizing a Gasoline Engine Using Turbocharging with Direct Injection', SAE paper 2003-01-0542. (2003)

8. PETITJEAN, D., BERNARDINI, L., MIDDLEMASS, C. and SHAHED, S.M., 'Advanced Gasoline Engine Turbocharging Technology for Fuel Economy Improvements', SAE paper 2004-01-0988. (2004)

9. WATSON, H.C., MILKINS, E.E., ROBERTS, K. and BRYCE, W., 'Turbocharging for Fuel Efficiency, SAE paper 830014. (1983)

10. ROSENKRANZ, H.G., WATSON, H.C., BRYCE, W. and LEWIS, A. 'Driveability fuel consumption and emissions of 1.3 litre turbocharged spark ignition engine developed as a replacement for a 2 litre normally aspirated engine.' Proc. I.Mech.E., C118/86:139-150 pp (1986)

11. ROSENKRANZ, H.G. and WATSON, H.C., 'Performance Comparison of Ceramic and Conventional Turbines in the Turbocharger of a 1.3L S.I. Engine', Mech.Eng. Dept., Univ. of Melbourne. Report T73/85 (1985)

12. ATTARD, W., WATSON, H.C. and STRYKER, P., 'Design and Development of a Gasketless Cylinder Head/Block Interface for an Open Deck, Multi Cylinder, Highly Turbocharged Small Engine', SAE paper 2006-32-0036. (2006)

13. ATTARD, W., WATSON, H.C. and KONIDARIS, S., 'Highly Turbocharging a Restricted Two Cylinder Small Engine - Turbocharger Development', SAE paper 07PFL-157. (2007)
14. WATSON, N. and JANOTA, M.S., 'Turbocharging the Internal Combustion Engine', Macmillan Press, ISBN 0-333-242904. (1982)

15. ROTHE, M., HEIDENREICH, T., SPICHER, U. and SCHUBERT, A., 'Knock Behaviour of SI Engines: Thermodynamic Analysis of Knock Onset Locations and Knock Intensities', SAE paper 2006-01-0225. (2006)

16. HARRALSON, J., 'Design of Racing and High Performance Engines', SAE book PT-53, ISBN 156091-601-X, (1995)

17. AS 4594.1-1999, 'Internal Combustion EnginesPerformance', Australian Standard. (1999)

18. TAYLOR, C.F., 'The Internal Combustion Engine in Theory and Practice', Vol. 1 and 2, ISBN 0262700271. (1977)

19. HEYWOOD, J., 'Internal Combustion Engine Fundamentals', ISBN 007028637X. (1988)

20. WATSON, H.C. and MILKINS, E.E., 'Cylinder Head Design', Modern engine developments Lecture 7246/1, University of Melbourne. (1972)

21. DAVIS, R.S. and PATTERSON, G.S., 'Cylinder Pressure Data Quality Checks and Procedures to Maximize Data Accuracy', SAE paper 2006-011346. (2006)

22. MacINNES, H., 'Turbochargers', HP Books, ISBN 0912656-49-2. (1984)

23. OTOBE, Y., GOTO, O., MIYANO, H., KAWAMOTO, M., AOKI, A. and OGAWA, T., 'Honda Formula 1 Turbocharged V6 1.5 liter Engine', SAE paper 890877. (1989)

24. CLOUGH, M.J., 'Precision Cooling of a Four Valve per Cylinder Engine', SAE paper 931123. (1993)

25. HAMORI, F., 'Exploring the Limits of Hydrogen Assisted Jet Ignition', Ph.D. Thesis, Mech.Eng. Dept, Univ. of Melbourne. (2006)

26. Automotive Engineering International, 'Traveling the long road to gasoline direct injection', SAE International, June (2006) 


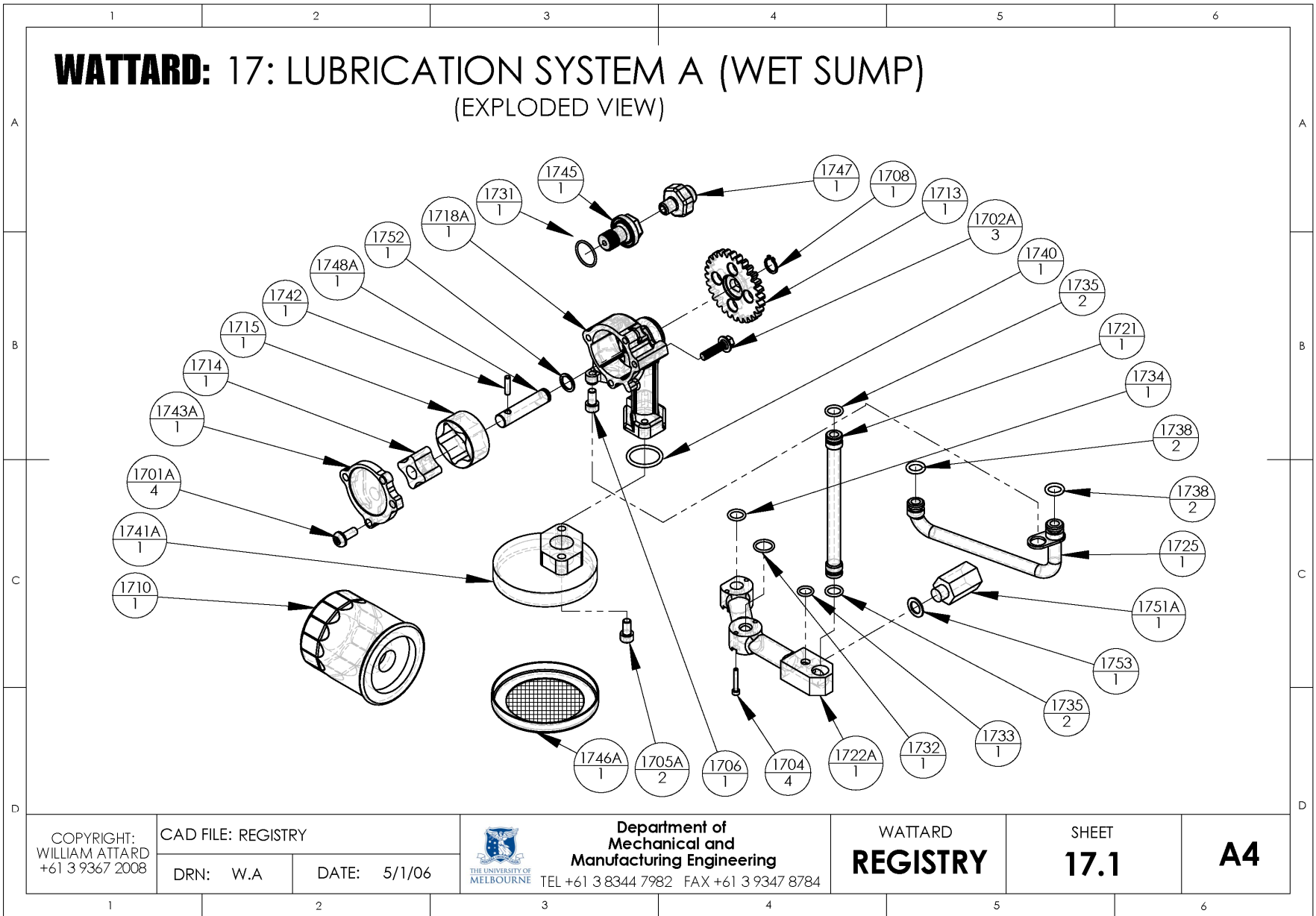

WATTARD: 17: LUBRICATION SYSTEM B (DRY SUMP) (EXPLODED VIEW)

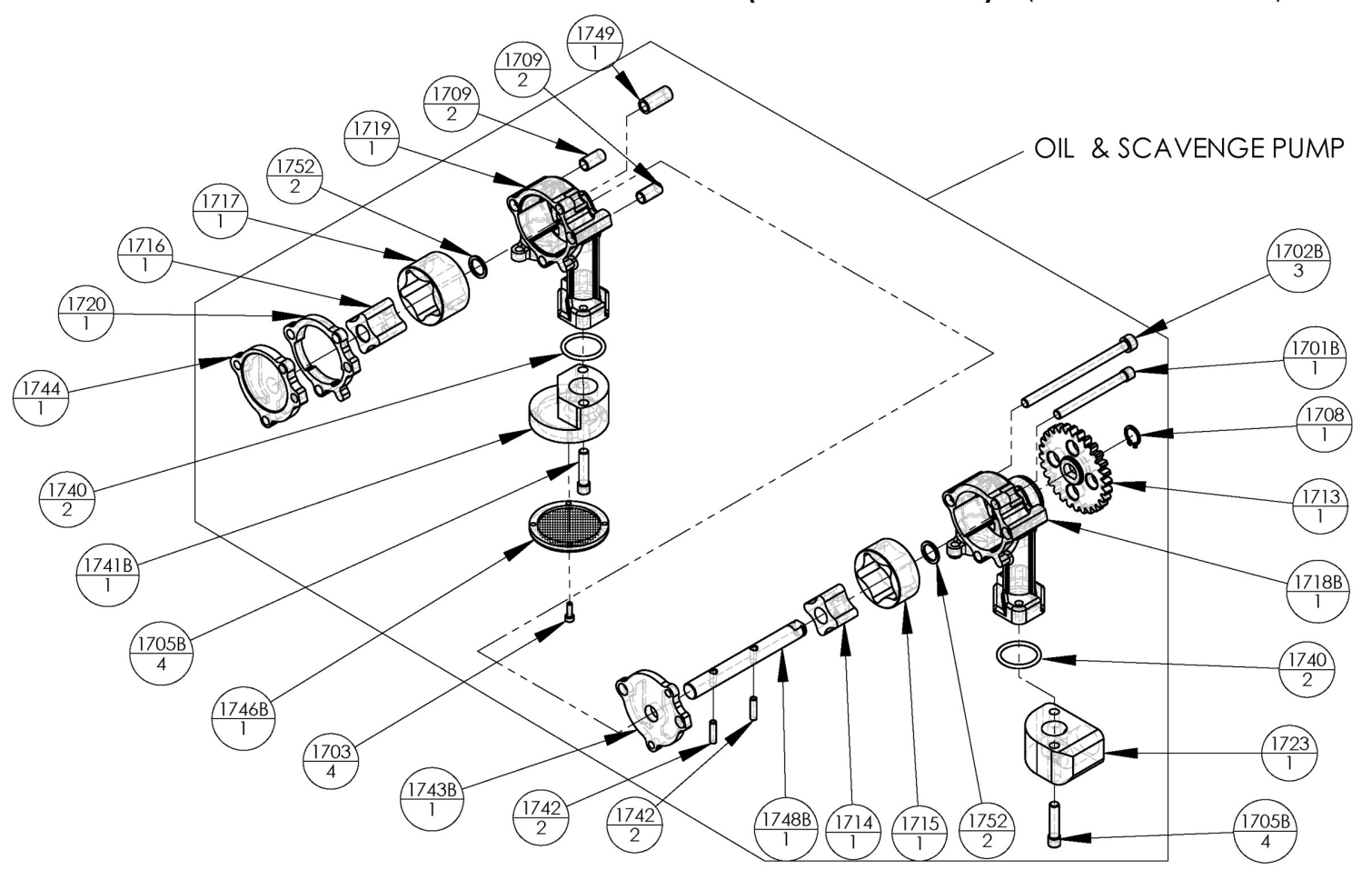

\begin{tabular}{|c|c|c|c|c|c|c|c|c|}
\hline \multirow{2}{*}{$\begin{array}{l}\text { COPYRIGHT: } \\
\text { WILLAMATARR } \\
+61393672008\end{array}$} & \multicolumn{3}{|l|}{ CAD FILE: REG } & \multirow{2}{*}{ 里. } & \multirow{2}{*}{$\begin{array}{c}\text { Department of } \\
\text { Meechanical and } \\
\text { Manufacturing Engineering } \\
\text { EL +61 } 383447982 \text { FAX }+61393478784\end{array}$} & \multirow{2}{*}{$\begin{array}{c}\text { WATARD } \\
\text { REGISTRY }\end{array}$} & \multirow{2}{*}{$\begin{array}{c}\text { SHEET } \\
\mathbf{1 7 . 2 A}\end{array}$} & \multirow{2}{*}{ A4 } \\
\hline & DRN: W.A & DATE: & $5 / 1 / 06$ & & & & & \\
\hline
\end{tabular}




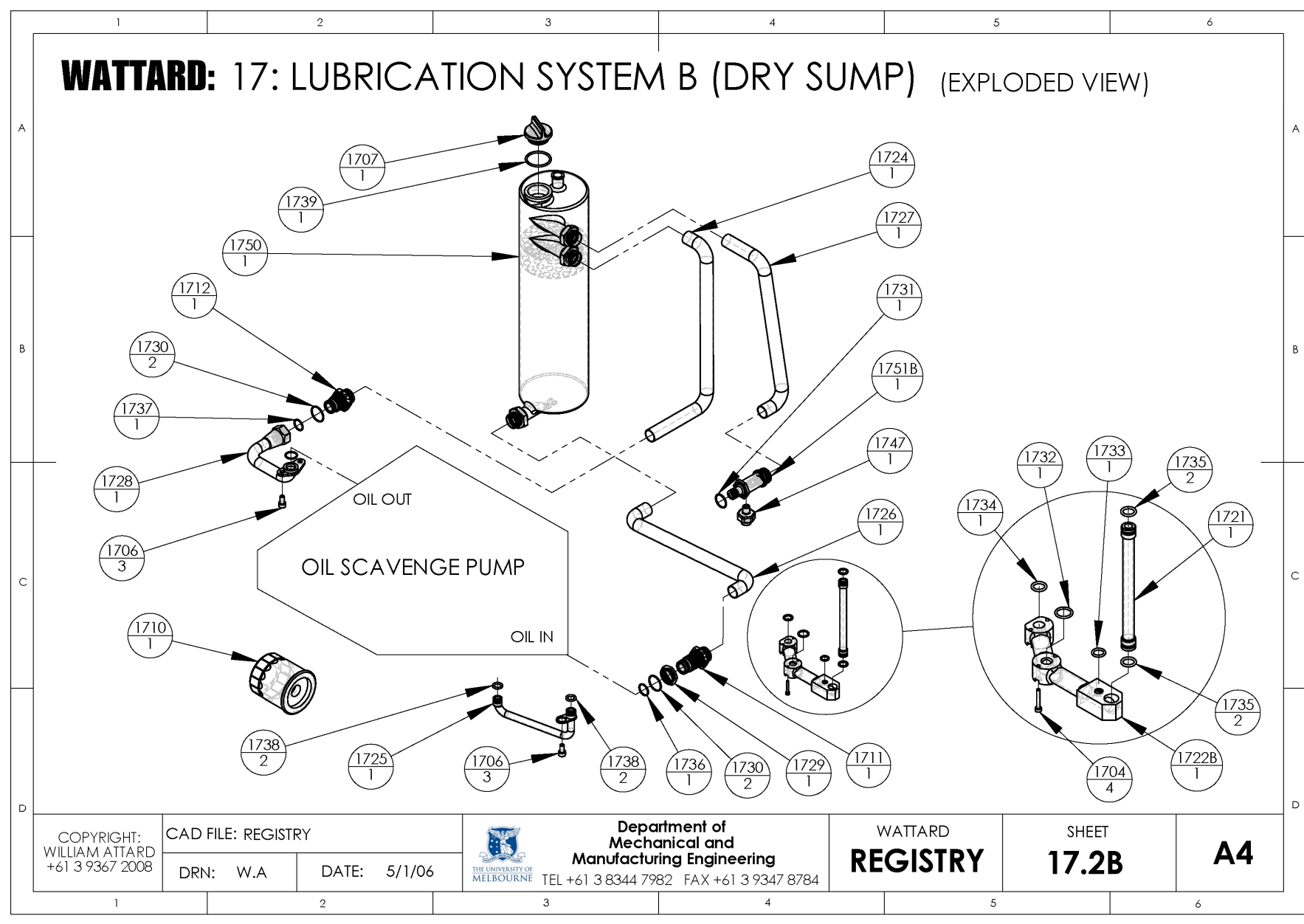

\section{WATTARD: 17: LUBRICATION SYSTEM (ASSEMBLIES \& PARTS)}

ASSEMBLY INDEX

\begin{tabular}{|c|l|l|c|}
\hline ASSY \# & \multicolumn{1}{|c|}{ DESCRIPTION } & CAD FILE & DRAWING \# \\
\hline 0017 & Lubrication system & 0017 A Lubrication system Assy A (wet sump) & $0017 A$ \\
& $0017 \mathrm{~B}$ Lubrication system Assy B (dry sump) & $0017 \mathrm{~B}$ \\
\hline
\end{tabular}

PART INDEX

\begin{tabular}{|c|c|c|c|c|}
\hline PART \# & QTY & DESCRIPTION & CAD FILE & DRAWING \# \\
\hline 1701 & AR & Bolt (oil pump back plate) & 1701A Bolt-PAN M6x 16 (oil pump back plate- wet sump) & $1701 \mathrm{~A}$ \\
\hline \multirow{2}{*}{1702} & \multirow{2}{*}{ AR } & \multirow{2}{*}{ Bolt (pump to casing) } & $1702 \mathrm{~A}$ Bolt-flanged M6×25 (pump to casing- wet sump) & $1702 \mathrm{~A}$ \\
\hline & & & 1702B Bolt-SHCS M6x90 (pump to casing- dry sump) & $1702 B$ \\
\hline 1703 & 4 & Bolt-SHCS (filter screen) & 1703 Bolt-SHCS M3×10 (filter screen) & 1703 \\
\hline 1704 & 4 & Bolt-SHCS (manifold oil line) & 1704 Bolt-SHCS M3×20 (manifold oil line) & 1704 \\
\hline \multirow{2}{*}{1705} & \multirow{2}{*}{ AR } & \multirow{2}{*}{ Bolt-SHCS (pump inlet) } & 1705A Bolt-SHCS M6x20 (pump inlet- wet sump) & $1705 \mathrm{~A}$ \\
\hline & & & 1705B Bolt-SHCS M6x25mod (pump inlet- dry sump) & 1705B \\
\hline 1706 & AR & Bolt-SHCS (pump oulet) & 1706 Bolt-SHCS M6x12 (pump oulet) & 1706 \\
\hline 1707 & 1 & Cap (oil tank) & 1707 Cap (oil tank) & 1707 \\
\hline 1708 & 1 & Circlip-external (pump shaft) & 1708 Circlip-external $11 \mathrm{~mm}$ (pump shaft) & 1708 \\
\hline 1709 & 2 & Dowell-hollow (oil pump to scav pump) & 1709 Dowell-hollow $8 \times 16$ (oil pump to scav pump) & 1709 \\
\hline 1710 & 1 & Filter-oil & 1710 Filter-oil & 1710 \\
\hline 1711 & 1 & Fitting (oil in) & 1711 Fitting (oil in) & 1711 \\
\hline 1712 & 1 & Fitting (oil out) & 1712 Fitting (oil out) & 1712 \\
\hline 1713 & 1 & Gear (pump drive) & 1713 Gear (pump drive) & 1713 \\
\hline 1714 & 1 & G-rotor (oil pump inner) & 1714 G-rotor (oil pump inner) & 1714 \\
\hline 1715 & 1 & G-rotor (oil pump outer) & 1715 G-rotor (oil pump outer) & 1715 \\
\hline 1716 & 1 & G-rotor (scav pump inner) & 1716 G-rotor (scav pump inner) & 1716 \\
\hline 1717 & 1 & G-rotor (scav pump outer) & 1717 G-rotor (scav pump outer) & 1717 \\
\hline \multirow{2}{*}{1718} & \multirow{2}{*}{1} & \multirow{2}{*}{ Housing (oil pump) } & 1718A Housing (oil pump- wet sump) & $1718 \mathrm{~A}$ \\
\hline & & & 1718B Housing (oil pump- dry sump) & $1718 \mathrm{~B}$ \\
\hline 1719 & 1 & Housing (scav pump) & 1719 Housing (scav pump) & 1719 \\
\hline 1720 & 1 & Housing-extension (scav pump) & 1720 Housing-extension (scav pump) & 1720 \\
\hline 1721 & 1 & Line-oil (manifold to head) & 1721 Line-oil (manifold to head) & 1721 \\
\hline \multirow{2}{*}{1722} & \multirow{2}{*}{1} & \multirow{2}{*}{ Line-oil (manifold) } & 1722A Line-oil (manifold- wet sump) & $1722 \mathrm{~A}$ \\
\hline & & & 1722B Line-oil (manifold- dry sump) & 1722B \\
\hline 1723 & 1 & Line-oil (oil in fitting to oil pump) & 1723 Line-oil (oil in fitting to oil pump) & 1723 \\
\hline 1724 & 1 & Line-oil (oil out fitting to oil tank) & 1724 Line-oil (oil out fitting to oil tank) & 1724 \\
\hline
\end{tabular}

D 


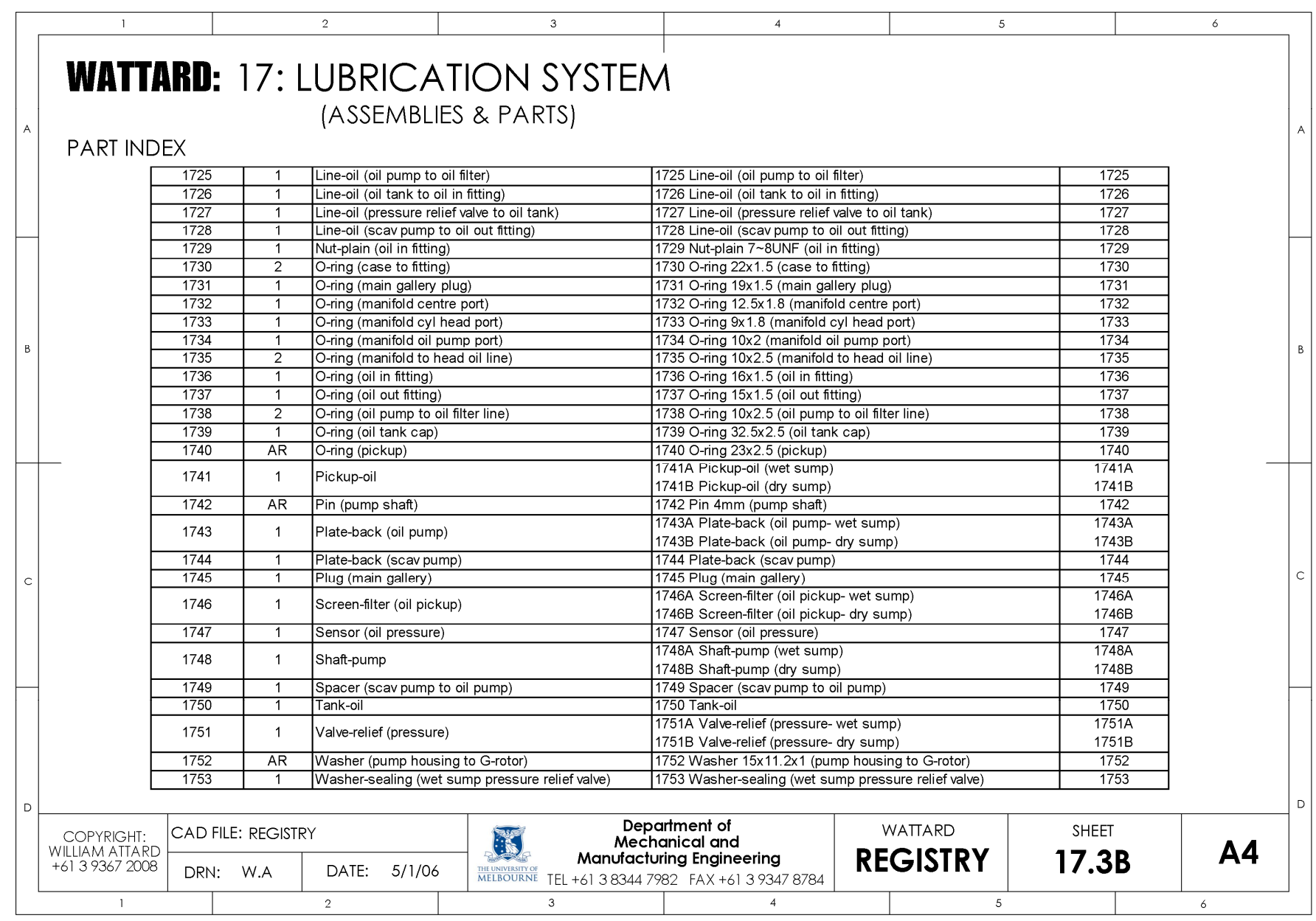




\section{University Library}

\section{- M M I N E R VA A gateway to Melbourne's research publications}

Minerva Access is the Institutional Repository of The University of Melbourne

Author/s:

Attard, William;Watson, Harry;Konidaris, Steven

Title:

Highly turbocharging a restricted, odd fire, two cylinder small engine: design, lubrication, tuning and control

Date:

2006

Citation:

Attard, W., Watson, H., \& Konidaris, S. (2006). Highly turbocharging a restricted, odd fire, two cylinder small engine: design, lubrication, tuning and control. In, Proceedings, SAE International Motorsports Engineering Conference \& Exhibition, Dearborn, Michigan, USA.

Publication Status:

Published

Persistent Link:

http://hdl.handle.net/11343/34452 